\title{
The Economic Penalty of Terrorism: Increase in Discrimination Against Arabs and Muslims after Paris Attacks
}

\author{
Sander Wagner*1 and Ivaylo D. Petev ${ }^{\dagger 2}$ \\ ${ }^{1}$ CREST, ENSAE, Institut Polytechnique de Paris \\ ${ }^{2}$ CREST, CNRS, Institut Polytechnique de Paris
}

November 6, 2019

*sander.wagner@ensae.f

†ivaylo.petev@ensae.fr

${ }^{1}$ We benefited from the research assistance of Tom Seimandi and Jacques Aguilera and feedback of Diederik Boertien, Felix Tropf and Xavier D'Haultfoeuille. We thank Thomas Le Barbanchon and Roland Rathelot for sharing with us their data on name classifications. This research was supported by a grant of the French National Research Agency (ANR), "Investissements d'Avenir" (Labex ECODEC-ANR-11-LABX-0047). 


\begin{abstract}
Economic transactions on online peer-to-peer platforms depend on buyers and sellers revealing personal information to facilitate exchanges with the unintended consequence that the information may become a source for discrimination. Using original panel data we show evidence of substantial discrimination against Arab/Muslim hosts in Airbnb's online rental market in Paris, France. Analysis of 41-months of online transaction data shows a substantial increase in discrimination following large-scale, deadly terrorist attacks in November 2015. Discrimination results in a foregone monthly revenue of at least 106 US dollars for Arab/Muslim hosts in the year before the November 2015 attacks, after which losses increase to at least 178 US dollars. Our results demonstrate the association of mass terrorism with a contraction of a large-scale market of the sharing economy, the cost of which falls disproportionately upon members of an ethnic and religious minority.
\end{abstract}




\section{Introduction}

The last two decades have been marked by the increase in frequency, lethality and visibility of Islamist terrorism in Western countries. An inevitable question is what influence the trend has on discrimination against individuals of Arab and Muslim descent. Terrorist attacks are rare, idiosyncratic and geographically situated local events. Their direct effect on discrimination in the general population is difficult to tell apart from the effect of alternative factors associated with changes in, among others, economic conditions (Legewie, 2013), media coverage and political discourse (Spilerman and Stecklov, 2009, Bail, 2012). Consequently, researchers focus on the short temporal window around terrorist attacks. The evidence points to their effect on anti-immigrant sentiment and Arab-related prejudices (Echebarria-Echabe and FernándezGuede, 2006; Finseraas and Listhaug, 2013; Legewie, 2013) whose repercussions have been shown, albeit not consistently (Braakmann 2010), to disadvantage individuals of Arab-Muslim descent in the housing (Gautier et al., 2009, Ratcliffe and von Hinke, 2015) and labour markets (Dávila and Mora, 2005; Kaushal et al., 2007; Glover, 2019, Rabby and Rodgers, 2011). But the evidence does not link the effect directly and systematically to an increase in discrimination practices and the focus on the immediate aftermath of terrorist attacks leaves open the question of whether the observed effects have long-term consequences.

In this study we show evidence of a direct effect of terrorism on discrimination against Arab/Muslim individuals with a lasting fallout. Using panel data on a large-scale online market for temporary vacation rentals in the French capital, Paris, we record non-negligible levels of discrimination throughout the year prior to large-scale, multi-sited deadly terrorist attacks in November 2015. After this time point, we measure a sizeable increase in discrimination whose level persists beyond the recovery of the market to pre-attacks levels and until our last data point in April 2018, two and a half years following the tragic events 1 . Our findings have added importance given that they reveal the impact of terrorism on weakly institutionalised, daily exchanges between mostly private individuals in a sector of the economy, the peer-to-peer online market, which has grown to involve millions of individuals worldwide.

In the following pages, we begin with a brief description of recent evidence on day-to-day discrimination in the sharing economy. A subsequent section situates our study in the literature on the effects of terrorism. The rest of the paper develops around the analysis of the empirical evidence in data on a large online market for temporary vacation rentals.

\section{Discrimination in the Sharing Economy}

The sharing economy is expanding to ever more aspects of social life. At the same time evidence that online markets provide platforms for day-to-day discrimination between strangers is also growing. Systematic discrimination in the traditional economy is a staple finding of social science research (Pager and Shepherd, 2008, Rich, 2014; Quillian et al., 2017). The sharing economy differs in two important ways however: first, it facilitates market exchanges between mostly private individuals, and second, the conclusion of an exchange is facilitated by seller and buyer revealing personal information. This information offers otherwise unobservable cues about the quality and experience of the marketed good or service and about the trustworthiness of the exchange (Diekmann et al., 2014; Abrahao et al., 2017). On certain online platforms like the product market eBay, revealed personal information during an exchange is minimal and not necessarily mutual, though still a source susceptible to produce discrimination (Nunley et al. 2011, Doleac and Stein, 2013, Ayres et al., 2015). But on peer-to-peer services, which involve the sharing of intimate personal space, during a commute for example, or the temporary rental, for instance, of one's vehicle or living quarters, the incentive for sellers and buyers to reveal, voluntarily and mutually, extensive personal information is so high as to become an essential feature of these market exchanges.

The spectacular growth of online peer-to-peer markets over the last decade results in hundreds of millions of individuals worldwide, who participate in market exchanges whereby they make choices based on the personal information of other private individuals. Absent sufficient legal safeguards (Todisco, 2015, Leong and Belzer, 2017;, Calo and Rosenblat, 2017) these choices are susceptible to reproduce long-standing prejudices and inequalities with economic consequences that disadvantage individuals on the basis of their

\footnotetext{
${ }^{1}$ The series of coordinated, multi-site terrorist attacks, which took place on the night of the 13th and the 14th of November 2015 in Paris and the city's northern suburb, Saint-Denis, caused the death of 130 people including more than 350 injured, almost 100 of whom seriously. The attacks, for which the Islamic State of Iraq and the Levant claimed responsibility, were the second deadliest in the European Union since the Madrid train bombings in 2004. Of the nine immediate perpetrators of the attacks, two were Iraqis, the others were French and Belgian citizens.
} 
gender, class, race, ethnicity and religion (Abrahao et al. 2017). A growing list of studies of such online peer-to-peer platforms offers evidence on the troubling extent of observed day-to-day discrimination.

Consider a few telling examples. A field experiment of riding services by transportation companies Uber and Lyft in two large U.S. cities found longer waiting time and higher cancellation rates for passengers who use African American sounding names as well as longer, more expensive rides for female passengers $(\mathrm{Ge}$ et al. 2016). In a similar vein analysis of the data of a German ride-sharing company found a discriminatory price premium of $32 \%$ for passengers with typically Arab, Persian or Turkish names (Tjaden et al. 2018). Several studies of the short-term rental company Airbnb showed lower acceptance rates in large U.S. cities for guests with African American names (Edelman and Luca, 2014; Cui et al., 2016), lower rental price rates for apartments of African American hosts in New York City (Edelman and Luca, 2014) and lower rental prices for Asian and Hispanic hosts in San Francisco (Kakar et al. 2018).

Edelman's findings on discrimination are an important reference for our study because we also analyse data from an Airbnb market, in our case the market in the French capital Paris. His precursory work, along with the aforementioned subsequent studies, illustrates that discriminatory practices on the basis of racial and ethnic identity, for which there is extensive historical evidence in the context of the traditional housing market in the United States (Massey, 2005; Pager and Shepherd, 2008), take place, at equally troubling levels, in daily exchanges between private individuals in the much more recent sharing economy of short-term vacation rentals. Notwithstanding differences in both institutions and in ethnic composition of minorities in Europe, there, too, exists extensive evidence of discrimination in national housing markets (Flage, 2018), including the French one (Acolin et al. 2016, Bunel et al. 2017, 2018, Le Gallo et al. 2018). Bridging evidence from both continents, a recent study of Airbnb from six U.S., three Canadian and ten West European large or capital cities, including Paris, shows that Edelman's findings extend beyond the American case and apply, with comparable amplitude, to Arab/Muslim individuals, North American and European alike (Laouénan and Rathelot |2017).

Discrimination in these Airbnb studies refers to observed differences between individuals whose ethnoracial origin is inferred from names which are stereotypically associated with a particular origin. Correspondence audit studies, which track discrimination through the count of positive responses to rental requests by fictitious Airbnb guests, suffer from potential bias due to association of social status with unique names (Gaddis, 2017). Studies using panel data on real Airbnb hosts, which measure discrimination based on variation in rental prices, limit the bias in so far as the data allow for the inclusion of controls for the characteristics of Airbnb listings. These capture elements of hosts' socio-economic status, among other potential determinants of a client's choice, associated with geographic location, rental availability and quality and reviews from previous guests. The addition of controls reduces observed raw differences significantly but does not erase completely the price gap, whose estimates range from $12 \%$ in New York City (Edelman and Luca, 2014) and 8 to 10\% in San Francisco (Kakar et al. 2018). Laouénan and Rathelot (2017) arrive at a lower overall estimate of $3.2 \%$ but their data originate from a considerably more heterogeneous population from sixteen cities and nine countries. A lingering question remains about whether the estimates reflect a taste for discrimination (i.e., racism) or statistical discrimination whereby clients use hosts' names as proxy for otherwise unobservable qualities of rentals between ethno-racial groups. Laouenan and Rathelot attribute three-quarters of the remaining price gap to statistical discrimination. Notwithstanding the variation in estimates across studies, the evidence appears conclusive as to the presence of systematic ethno-racial discrimination in the Airbnb market for temporary vacation rentals.

\section{Terrorism's Effects on Discrimination}

The presence of discriminatory practices in the sharing economy, the Airbnb market in particular, however consistent the evidence is across cities and ethno-racial minorities, leaves open the question of the likelihood of them increasing under the influence of a terrorist attack. The findings of recent research on the topic may seem to tilt the balance towards an affirmative answer. Studies have shown a systematic and widespread effect of terrorism on public opinion. A rise in anti-immigrant sentiment and Arab- and Muslim-related prejudices has been registered in European societies independent of whether terrorist attacks took place on local territory like the bombings in Madrid in 2004 (Legewie, 2013; Echebarria-Echabe and Fernández-Guede, 2006) or far from home countries like the 9/11 events in the United States (Âslund and Rooth, 2005; Sheridan, 2006, Schüller, 2016) and the targeting of foreign nationals in Bali in 2002 (Legewie, 2013) and in Mumbai in 2008 (Finseraas and Listhaug, 2013). In some of these cases the shift in 
public opinion has been linked to changes in behavior such as post-9/11 increases in party-defections (from left-wing membership), political donations and voting (Hersh 2013) as well as an outright change in the outcome in parliamentary elections occuring only three days after the Madrid bombings (Montalvo, 2011). The effect of terrorism on public opinion has been also shown to have adverse economic consequences on Arab and Muslim minorities, observed in declines in earnings in the U.S. (Kaushal et al. 2007; Dávila and Mora, 2005) and in employment in the U.S. (Rabby and Rodgers, 2011) and in France (Glover, 2019). And, in direct relation to our area of analysis, a decline in housing prices and sales in majority Muslim neighbourhoods has been measured in the aftermath of attacks in Amsterdam (Gautier et al. 2009) and in London (Ratcliffe and von Hinke, 2015).

But the evidence leaves out a few crucial blind spots. First of all, in so far as research on public opinion focuses on changes in the immediate aftermath of attacks, it is unclear how the effect reverberates over time. It has been shown (Hopkins, 2010) that post-attack spikes in anti-immigrant sentiment dissipate rapidly, within a few months, in line with evidence on the short-term duration of associated psychological effects like post-traumatic stress disorder (Silver et al., 2002), of behavioral reactions like the substitution of air travel after the attacks of 9/11 (Gigerenzer. 2006) and of collective emotions and pro-social behavior following the November 2015 attacks in Paris (Garcia and Rimé, 2019). Second, research tracking effects in a longer temporal window (i.e., one to three years) like some of the aforementioned studies on economic outcomes does not rely on perfectly settled evidence. There are also studies which find an effect of terrorism on attitudes but none on labor market outcomes for Arab-Muslim individuals in the U.S. (Wang, 2018), Australia (Goel, 2010), Sweden (Åslund and Rooth, 2005) and Germany (Braakmann, 2009) following the 9/11 attacks and in London following the 2007 bombings there (Braakmann 2010). Finally, in the studies that do observe an effect of terrorism, its translation into an increase in discrimination is largely assumed rather than measured directly, with explicit reference to individual or institutional practices that disadvantage ethnic minorities.

The Paris Airbnb market under scrutiny in our study provides the means to address these blind spots. It is a mature market in so far as it represents the largest Airbnb metropolitan economy with more than seventy thousand unique offerings. Individuals of Arab and/or Muslim origin, who we identify based on self-reported names on hosts' Airbnb profiles, make up a sizable population in this market. They are part of the largest ethnic minority in France (Tribalat, 2015; Beauchemin et al. 2016), many of whom are second or third generation French citizens and are concentrated in and around the city of Paris (Aubry and Tribalat, 2011). Given the relatively weak institutionalization and low legal safeguards (Todisco, 2015. Leong and Belzer, 2017, Calo and Rosenblat, 2017) of the Airbnb market, peer-to-peer exchanges play a central enough role to assume that any observed differences disadvantaging Arab-Muslim hosts emanate primarily from interactions between hosts and guests who are mostly private individuals. Armed with panel data running from November 2014 to March 2018, we are thus able to track peer-to-peer exchanges, to verify the presence of any discrimination and to observe changes in the immediate aftermath of the large-scale, deadly terrorist attacks of November 2015 and beyond, up to two and a half years later. In the following sections we elaborate on how our research design deals with the aforementioned challenges as we present the data and the methodology and analyze the empirical results.

\section{Data}

To examine discrimination on the Airbnb market we analysed monthly panel data on all rentals listed in the city of Paris between November 2014 and March 2018. The data were purchased from AIRDNA, a short-term rental data and analytics company. They include exact monthly information on the number of days a property was listed as available and the number of days it was rented out in a given month along with the corresponding rental price. The data capture additional descriptive information on listing properties which is available to customers on the Airbnb website. We restrict the analysis to a sample of hosts whose names we can identify as uniquely French or Arab/Muslim. We analyze only monthly observations for which the hosts' properties were listed as available for rent for at least one day. The resulting dataset consists of 1,044,022 monthly observations for 72,991 distinct properties over a time period of 41 months.

We categorize variables into the following groups: dependent variables $Y_{i}$, host characteristics $H_{i}$, neighborhood characteristics $N_{i}$, time-invariant listing characteristics $L_{i}$, time variant listing characteristics $l_{i t}$ and reviews $r_{i t}$.

Our two dependent variables are occupancy rate and log price. Occupancy rate is measured by dividing 
Table 1: Descriptive Statistics: Mean (Standard Deviation)

\begin{tabular}{|c|c|c|c|c|c|c|}
\hline & $\begin{array}{r}\text { French } \\
\text { All Months }\end{array}$ & $\begin{array}{l}\text { Arab/Muslim } \\
\text { All Months }\end{array}$ & $\begin{array}{r}\text { French } \\
\text { Jan. } 2015\end{array}$ & $\begin{array}{l}\text { Arab/Muslim } \\
\text { Jan. } 2015\end{array}$ & $\begin{array}{r}\text { French } \\
\text { Jan. } 2018\end{array}$ & $\begin{array}{l}\text { Arab/Muslim } \\
\text { Jan. } 2018\end{array}$ \\
\hline Female & $\begin{array}{c}0.52 \\
(0.50)\end{array}$ & $\begin{array}{c}0.54 \\
(0.50)\end{array}$ & $\begin{array}{c}0.51 \\
(0.50)\end{array}$ & $\begin{array}{c}0.56 \\
(0.50)\end{array}$ & $\begin{array}{c}0.51 \\
(0.50)\end{array}$ & $\begin{array}{c}0.53 \\
(0.50)\end{array}$ \\
\hline Avg. Daily Rate in USD & $\begin{array}{c}128.68 \\
(105.37)\end{array}$ & $\begin{array}{l}105.89 \\
(73.58)\end{array}$ & $\begin{array}{c}138.09 \\
(102.49)\end{array}$ & $\begin{array}{l}114.82 \\
(66.38)\end{array}$ & $\begin{array}{c}146.04 \\
(121.13)\end{array}$ & $\begin{array}{l}116.92 \\
(85.48)\end{array}$ \\
\hline Occupancy Rate & $\begin{array}{c}0.28 \\
(0.35)\end{array}$ & $\begin{array}{c}0.24 \\
(0.33)\end{array}$ & $\begin{array}{c}0.24 \\
(0.30)\end{array}$ & $\begin{array}{c}0.25 \\
(0.31)\end{array}$ & $\begin{array}{c}0.28 \\
(0.35)\end{array}$ & $\begin{array}{c}0.23 \\
(0.34)\end{array}$ \\
\hline No. of Days Reserved & $\begin{array}{c}7.00 \\
(9.36)\end{array}$ & $\begin{array}{c}6.05 \\
(8.98)\end{array}$ & $\begin{array}{c}5.34 \\
(7.79)\end{array}$ & $\begin{array}{c}6.07 \\
(8.51)\end{array}$ & $\begin{array}{c}7.09 \\
(9.77)\end{array}$ & $\begin{array}{c}6.02 \\
(9.33)\end{array}$ \\
\hline No. of Days Listed & $\begin{array}{l}24.75 \\
(8.72)\end{array}$ & $\begin{array}{l}26.21 \\
(7.75)\end{array}$ & $\begin{array}{l}22.15 \\
(9.99)\end{array}$ & $\begin{array}{l}23.33 \\
(9.54)\end{array}$ & $\begin{array}{l}26.02 \\
(8.87)\end{array}$ & $\begin{array}{l}27.37 \\
(7.66)\end{array}$ \\
\hline Revenue in USD & $\begin{array}{c}867.73 \\
(1543.10)\end{array}$ & $\begin{array}{c}626.15 \\
(1168.65)\end{array}$ & $\begin{array}{c}667.56 \\
(1118.62)\end{array}$ & $\begin{array}{c}649.42 \\
(1024.81)\end{array}$ & $\begin{array}{c}972.02 \\
(1746.17)\end{array}$ & $\begin{array}{c}697.26 \\
(1427.96)\end{array}$ \\
\hline No. of Guests & $\begin{array}{c}3.12 \\
(1.54)\end{array}$ & $\begin{array}{c}2.98 \\
(1.37)\end{array}$ & $\begin{array}{c}3.31 \\
(1.58)\end{array}$ & $\begin{array}{c}3.24 \\
(1.44)\end{array}$ & $\begin{array}{c}3.10 \\
(1.56)\end{array}$ & $\begin{array}{c}2.93 \\
(1.43)\end{array}$ \\
\hline No. of Bedrooms & $\begin{array}{c}1.10 \\
(0.81)\end{array}$ & $\begin{array}{c}0.93 \\
(0.73)\end{array}$ & $\begin{array}{c}1.21 \\
(0.83)\end{array}$ & $\begin{array}{c}1.03 \\
(0.77)\end{array}$ & $\begin{array}{c}1.10 \\
(0.82)\end{array}$ & $\begin{array}{c}0.92 \\
(0.73)\end{array}$ \\
\hline No. of Bathrooms & $\begin{array}{c}1.10 \\
(0.39)\end{array}$ & $\begin{array}{c}1.06 \\
(0.31)\end{array}$ & $\begin{array}{c}1.12 \\
(0.40)\end{array}$ & $\begin{array}{l}1.09 \\
(0.34)\end{array}$ & $\begin{array}{c}1.10 \\
(0.40)\end{array}$ & $\begin{array}{c}1.06 \\
(0.28)\end{array}$ \\
\hline Shared Room & $\begin{array}{c}0.01 \\
(0.09)\end{array}$ & $\begin{array}{c}0.01 \\
(0.12)\end{array}$ & $\begin{array}{c}0.00 \\
(0.07)\end{array}$ & $\begin{array}{c}0.01 \\
(0.07)\end{array}$ & $\begin{array}{c}0.01 \\
(0.09)\end{array}$ & $\begin{array}{c}0.02 \\
(0.13)\end{array}$ \\
\hline Private Room & $\begin{array}{c}0.11 \\
(0.31)\end{array}$ & $\begin{array}{c}0.12 \\
(0.32)\end{array}$ & $\begin{array}{c}0.09 \\
(0.29)\end{array}$ & $\begin{array}{c}0.10 \\
(0.30)\end{array}$ & $\begin{array}{c}0.12 \\
(0.32)\end{array}$ & $\begin{array}{c}0.13 \\
(0.33)\end{array}$ \\
\hline Entire Home/ Apartment & $\begin{array}{c}0.88 \\
(0.32)\end{array}$ & $\begin{array}{c}0.87 \\
(0.34)\end{array}$ & $\begin{array}{c}0.91 \\
(0.29)\end{array}$ & $\begin{array}{c}0.89 \\
(0.31)\end{array}$ & $\begin{array}{c}0.87 \\
(0.33)\end{array}$ & $\begin{array}{c}0.85 \\
(0.35)\end{array}$ \\
\hline Cancellation: Strict & $\begin{array}{c}0.37 \\
(0.48)\end{array}$ & $\begin{array}{c}0.32 \\
(0.47)\end{array}$ & $\begin{array}{c}0.47 \\
(0.50)\end{array}$ & $\begin{array}{c}0.45 \\
(0.50)\end{array}$ & $\begin{array}{c}0.39 \\
(0.49)\end{array}$ & $\begin{array}{c}0.34 \\
(0.47)\end{array}$ \\
\hline Cancellation: Moderate & $\begin{array}{c}0.29 \\
(0.46)\end{array}$ & $\begin{array}{c}0.26 \\
(0.44)\end{array}$ & $\begin{array}{c}0.33 \\
(0.47)\end{array}$ & $\begin{array}{c}0.33 \\
(0.47)\end{array}$ & $\begin{array}{c}0.30 \\
(0.46)\end{array}$ & $\begin{array}{c}0.26 \\
(0.44)\end{array}$ \\
\hline Cancellation: Flexible & $\begin{array}{c}0.33 \\
(0.47)\end{array}$ & $\begin{array}{c}0.42 \\
(0.49)\end{array}$ & $\begin{array}{c}0.19 \\
(0.40)\end{array}$ & $\begin{array}{c}0.23 \\
(0.42)\end{array}$ & $\begin{array}{c}0.31 \\
(0.46)\end{array}$ & $\begin{array}{c}0.40 \\
(0.49)\end{array}$ \\
\hline No. of Photos & $\begin{array}{c}14.75 \\
(10.05)\end{array}$ & $\begin{array}{l}12.67 \\
(9.35)\end{array}$ & $\begin{array}{c}18.18 \\
(10.62)\end{array}$ & $\begin{array}{c}17.73 \\
(11.81)\end{array}$ & $\begin{array}{c}14.60 \\
(10.02)\end{array}$ & $\begin{array}{l}12.32 \\
(8.80)\end{array}$ \\
\hline Minimum Stay & $\begin{array}{c}1.47 \\
(0.56)\end{array}$ & $\begin{array}{c}1.33 \\
(0.52)\end{array}$ & $\begin{array}{c}1.53 \\
(0.53)\end{array}$ & $\begin{array}{c}1.43 \\
(0.51)\end{array}$ & $\begin{array}{c}1.54 \\
(0.65)\end{array}$ & $\begin{array}{c}1.38 \\
(0.58)\end{array}$ \\
\hline Instantbook & $\begin{array}{c}0.17 \\
(0.37)\end{array}$ & $\begin{array}{c}0.21 \\
(0.41)\end{array}$ & $\begin{array}{c}0.12 \\
(0.33)\end{array}$ & $\begin{array}{c}0.17 \\
(0.38)\end{array}$ & $\begin{array}{c}0.21 \\
(0.41)\end{array}$ & $\begin{array}{c}0.24 \\
(0.43)\end{array}$ \\
\hline Business Ready & $\begin{array}{c}0.21 \\
(0.41)\end{array}$ & $\begin{array}{c}0.19 \\
(0.39)\end{array}$ & $\begin{array}{c}0.41 \\
(0.49)\end{array}$ & $\begin{array}{c}0.40 \\
(0.49)\end{array}$ & $\begin{array}{c}0.05 \\
(0.21)\end{array}$ & $\begin{array}{c}0.03 \\
(0.16)\end{array}$ \\
\hline Super Host & $\begin{array}{c}0.06 \\
(0.25)\end{array}$ & $\begin{array}{c}0.03 \\
(0.17)\end{array}$ & $\begin{array}{c}0.09 \\
(0.28)\end{array}$ & $\begin{array}{c}0.04 \\
(0.19)\end{array}$ & $\begin{array}{c}0.09 \\
(0.29)\end{array}$ & $\begin{array}{c}0.05 \\
(0.22)\end{array}$ \\
\hline No. of Reviews & $\begin{array}{c}14.94 \\
(28.21)\end{array}$ & $\begin{array}{c}12.80 \\
(25.84)\end{array}$ & $\begin{array}{c}19.48 \\
(27.32)\end{array}$ & $\begin{array}{c}20.58 \\
(26.99)\end{array}$ & $\begin{array}{c}19.92 \\
(36.32)\end{array}$ & $\begin{array}{c}16.91 \\
(32.20)\end{array}$ \\
\hline Rating: Overall & $\begin{array}{c}8.94 \\
(1.69)\end{array}$ & $\begin{array}{c}8.65 \\
(1.73)\end{array}$ & $\begin{array}{c}8.48 \\
(2.61)\end{array}$ & $\begin{array}{c}8.18 \\
(2.69)\end{array}$ & $\begin{array}{c}9.15 \\
(1.16)\end{array}$ & $\begin{array}{c}8.82 \\
(1.34)\end{array}$ \\
\hline Rating: Communication & $\begin{array}{c}9.41 \\
(1.69)\end{array}$ & $\begin{array}{c}9.30 \\
(1.69)\end{array}$ & $\begin{array}{c}8.86 \\
(2.69)\end{array}$ & $\begin{array}{c}8.68 \\
(2.81)\end{array}$ & $\begin{array}{c}9.60 \\
(1.11)\end{array}$ & $\begin{array}{c}9.47 \\
(1.18)\end{array}$ \\
\hline Rating: Accuracy & $\begin{array}{c}9.21 \\
(1.72)\end{array}$ & $\begin{array}{c}8.99 \\
(1.76)\end{array}$ & $\begin{array}{c}8.65 \\
(2.64)\end{array}$ & $\begin{array}{c}8.38 \\
(2.74)\end{array}$ & $\begin{array}{c}9.43 \\
(1.17)\end{array}$ & $\begin{array}{c}9.16 \\
(1.35)\end{array}$ \\
\hline Rating: Cleanliness & $\begin{array}{c}8.92 \\
(1.80)\end{array}$ & $\begin{array}{c}8.56 \\
(1.90)\end{array}$ & $\begin{array}{c}8.42 \\
(2.64)\end{array}$ & $\begin{array}{c}8.09 \\
(2.74)\end{array}$ & $\begin{array}{c}9.11 \\
(1.32)\end{array}$ & $\begin{array}{c}8.68 \\
(1.58)\end{array}$ \\
\hline Rating: Check In & $\begin{array}{c}9.38 \\
(1.70)\end{array}$ & $\begin{array}{c}9.23 \\
(1.72)\end{array}$ & $\begin{array}{c}8.82 \\
(2.67)\end{array}$ & $\begin{array}{c}8.57 \\
(2.82)\end{array}$ & $\begin{array}{c}9.58 \\
(1.11)\end{array}$ & $\begin{array}{c}9.42 \\
(1.23)\end{array}$ \\
\hline Rating: Location & $\begin{array}{c}9.26 \\
(1.69)\end{array}$ & $\begin{array}{c}9.17 \\
(1.67)\end{array}$ & $\begin{array}{c}8.69 \\
(2.65)\end{array}$ & $\begin{array}{c}8.47 \\
(2.78)\end{array}$ & $\begin{array}{c}9.50 \\
(1.09)\end{array}$ & $\begin{array}{c}9.38 \\
(1.16)\end{array}$ \\
\hline Observations & 942720 & 101302 & 7897 & 594 & 26558 & 3159 \\
\hline
\end{tabular}


the number of days a listing was rented out in a given month by the number of days it was listed as available for rental on the website. A listing on Airbnb has several prices as hosts can set different rates depending on length of visit. Further, cleaning fees are added to the overall price. Most work done on Airbnb so far looks at the daily price rate hosts demand (Edelman and Luca, 2014, Laouénan and Rathelot, 2017). Our data has the advantage that in addition to scraped prices from the Airbnb website we have information on when and for what price a listing was rented out. This allows us to measure the rate a listing was rented out for each day it was booked. Taking the average of those daily prices for all days a listing was rented out in a month gives our price variable. We take the log of the price variable in order to obtain coefficients that can be interpreted as elasticities. The advantage of this approach is that we exclude properties with listed prices but no solicited rental and hence measure discrimination on prices actually paid by consumers. This also avoids having our price data distorted by host strategies, such as setting high daily prices and low weekly or monthly rates in order to attract more long term rentals, etc. The disadvantage is that listings, which were not rented out in a given month, are excluded from the sample. In modelling price, we therefore use a limited sample of 522,991 monthly observations. In order to assure that different results for price and occupancy rate are not driven by this sample reduction for the price variable, we redo all analysis on occupancy rates on this smaller sample as a robustness check.

Discrimination, our explanatory variable of interest, is measured via Airbnb host names. We classified these as distinctly Arab/Muslim or typically French using lists of names applied in two previous studies (Laouénan and Rathelot, 2017; Behaghel et al., 2015). We complement these lists with publicly available data on the French government's opengouv.fr website which is based on work on the etymology of first names.

As control variables we incorporate all information on the characteristics of the listing that is visible to a visitor of the Airbnb website with the exception of visual content and written descriptions. Time invariant listing information includes the number of guests, the number of bedrooms, the number of bathrooms, and dummy variables for the type of the listing, which can either be a shared room (with another guest or inhabitant), a private room (in a house or apartment generally inhabited by the host or shared with other guests) or an entire home/apartment. Time variant listing information includes dummies for whether the cancellation policy is strict, moderate or flexible, resulting in different possible times and reimbursements for cancellation; the number of photos listed on the listing site; the minimum stay period specified; if instantbooking is enabled; if a host has superhost status; and if a listing has business ready status. The appendix provides detailed descriptions of these certification variables.

Review variables measure the amount and type of reviews a listing has received by former guests up to the month we observe the listing. They include the number of reviews, the overall rating as well as the rating for quality of communication, accuracy of descriptions, cleanliness, check-in and location. The overall rating for a listing is shown on a scale of 0.0 to 5.0 and thus includes 50 possible values. The ratings on particular items go up to 5 stars, with the possibility of showing half stars, and thus include 10 categories. We re-scaled all rating variables to go from 0 to 10 .

Finally, we create neighbourhood variables to control for the spatial distribution of listings. Using geocoded information on the listings we divided the city into 81 neighborhood zones which we use as dummy controls. We further assigned listings to 13 designated tourist zones as published by the Mairie de Paris (Paris City Hall) on their Open Data website, which overlap with the 81 neighborhood zones. We included each of these tourist zones as additional dummy control variables for spatial effects. (Fig 3 in the Appendix displays the 81 Airbnb districts in grey and the 13 tourist zones in blue and Fig 4 and Fig 5 show the distribution of Arab/Muslim names and prices across the 81 zones.)

Table 1 summarizes descriptive statistics of these variables for the entire panel as well for the January 2015 and January 2018 monthly cross-sections. The latter provide monthly snapshots of data from the beginning and end of our sample, which are comparable without being affected by monthly seasonality patterns.

Since Airbnb is a marketplace in which listings can enter and exit we also looked at its evolution over time. The number of available listings tripled over the 41 months we observed with hosts having Arab/Muslim names making up 7\% of available listings in November 2014 and 9\% in March 2018 (see Fig. 6). There was no notable effect of the November 2015 terrorist attacks on the upward trend in the number of listings or on the relative share of listings by Arab/Muslim hosts. Throughout the entire observed time period we also found no substantive differences between the rates of French and Arab/Muslim host listings exiting the market, which we defined as the last date a listing was actively rented out (see Fig. 7). 


\section{Methods}

We use three different methodological approaches to measure discrimination against Arab/Muslim hosts. First, we estimate a random effects panel model predicting log price and occupancy rates using host and listing characteristics, which gives us an indication of the average price and occupancy rate discount hosts with Arab/Muslim names face, conditional on the characteristics of their listings. Second, we run repeated OLS regressions, for every month in our sample and look at the monthly coefficients for being Arab/Muslim hosts which gives us a sense of the evolution of discrimination over time and allows us to assess the effects of the November 2015 terrorist attacks. Third, we employ fixed effects models, using a difference in difference strategy to look specifically at how the average strength of discrimination changes from the time period before to that after the November 2015 attacks.

To assess average levels of discrimination across the entire observed time period we estimate three nested random effects models. We first look at raw differences between hosts beyond the effect of time controls, then examine these differences following the inclusion of effects of listing characteristics and neighbourhoods and, in a third model, of reviews.

Model (1) looks at the raw effect of host name $H_{i}$ on occupancy rate or log price $y_{i t}$, after controlling only for a set of monthly time dummies $d_{t}$ :

$$
y_{i t}=\alpha+\beta H_{i}+\eta_{t} d_{t}+v_{i t}
$$

Model (2) adds neighborhood spatial controls $N_{i}$ and controls for time invariant listing characteristics, $L_{i}$ and time variant ones $l_{i t}$ :

$$
y_{i t}=\alpha+\beta H_{i}+\gamma N_{i}+\delta_{1} L_{i}+\delta_{2} l_{i t}+\eta_{t} d_{t}+v_{i t}
$$

Model (3) adds information on reviews $r_{i t}$ :

$$
y_{i t}=\alpha+\beta H_{i}+\gamma N_{i}+\delta_{1} L_{i}+\delta_{2} l_{i t}+\gamma r_{i t}+\eta_{t} d_{t}+v_{i t}
$$

The coefficient $\beta$ captures how much lower occupancy rates are and by what percentage prices are lower for hosts with typically Arab/Muslim instead of French names, conditional on the controls included in each model. We used log price and thus obtain an elasticity for price, but not log occupancy rate, since we have many values of zero for occupancy rates in our data. A key assumption of the random effects model is that the individual (listing) level error term is not correlated with the predictors. Under this assumption we can interpret $\beta$ as the degree of discrimination a host faces due to his or her ethnicity. The fact that a guest's booking decision is made based on the information on the website, which we incorporate in the last two models, lends credibility to this assumption.

To evaluate if discrimination against Arab/Muslim hosts changed over time we estimate Ordinary Least Squares (OLS hereafter) regression models for each month $t$ in our panel. The dependent and explanatory variables remain the same as in the random effects model. The $\beta_{t}$ now yields the effect of having an Arab/Muslim name compared to a French name in month $t$. We use an event study approach, analyzing the evolution of coefficients, to discern whether discriminatory patterns changed around the date of the November 2015 terrorist attacks in Paris.

Finally we assess the effects of the November 2015 attacks again estimating a listing fixed effects model. The advantage of this approach is that any time invariant listing characteristics - in particular, the description of listings, the quality of photos and the neighborhood - will not bias our estimates. However, we cannot include our variable on whether hosts have Arab/Muslim or French names because this is a time-invariant characteristic. Instead we use a difference in differences strategy, by looking at the interaction of being a host with an Arab/Muslim name with observations following the November 2015 attacks:

$$
y_{i t}=\alpha+\beta p a_{t}+\gamma A / M_{i} * p a_{t}+\delta l_{i t}+\theta r_{i t}+\eta L D_{i}+v_{i t}
$$

We now only include the listing time variant characteristics $l_{i t}$ and review variables $r_{i t}$ as controls. $L D_{i}$ are the listing dummies included in the listing fixed effects approach and $p a$ is a post-attacks dummy variable, which takes the value of 1 for observations after the November 2015 attacks up to March 2018 and the value of 0 for those prior to November 2015. We exclude observations for November 2015 from the sample. Our parameter of interest is the coefficient $\gamma$ for our interaction variable $A / M * p a$, which estimates whether the effect on price and occupancy rates of being an Arab/Muslim host changes after the November 2015 attacks. 


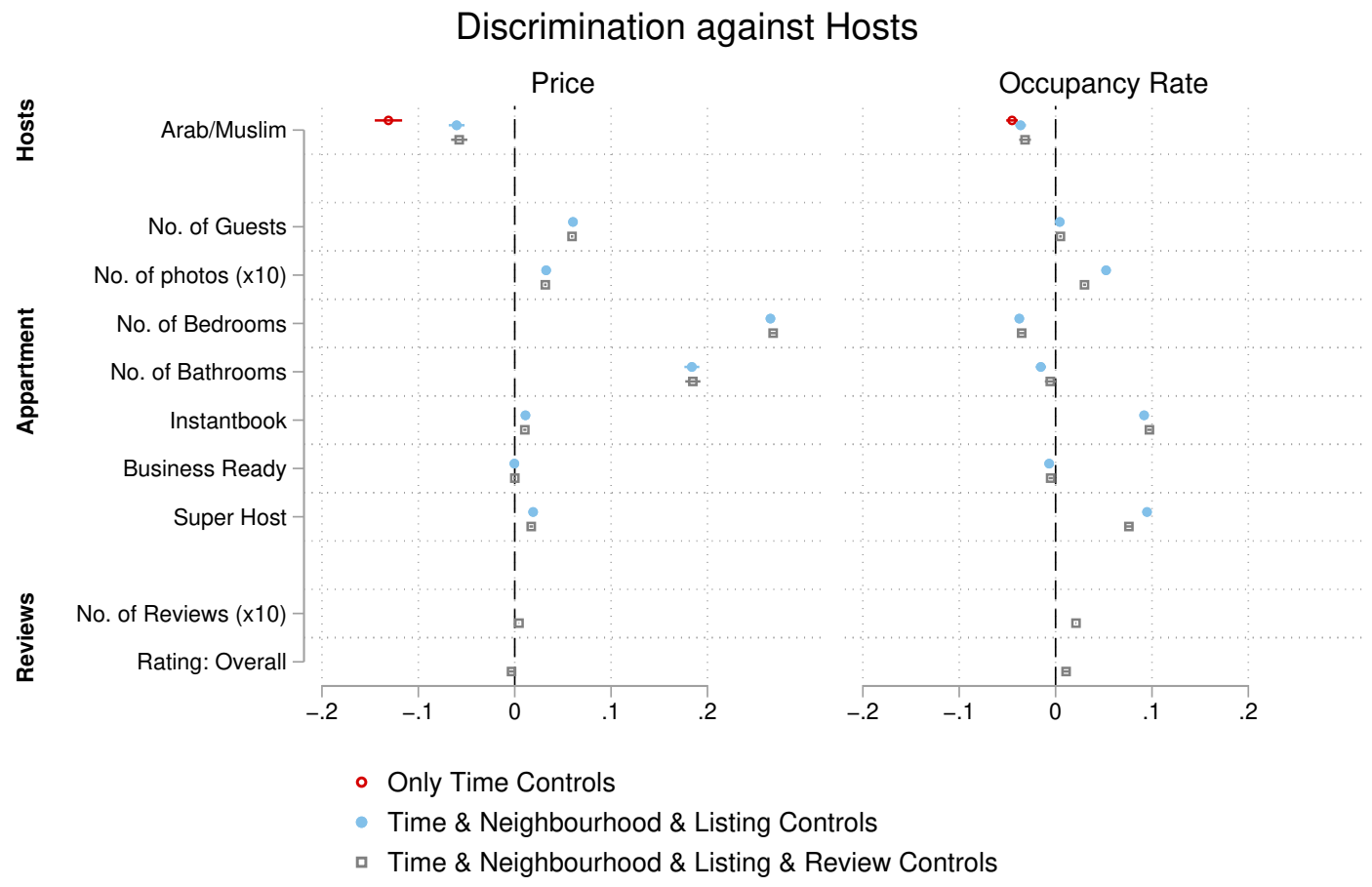

Figure 1: Selected coefficients from random effects models for listing price and occupancy rate with $95 \%$ confidence intervals. Price coefficients are elasticities, occupancy rate coefficients indicate change in percentage levels.

While the listing fixed effects model has the advantage of controlling for unobserved time-invariant listing characteristics, its disadvantage is that the sample of hosts we estimate these effects on is significantly smaller and more selective. Only listings which were in the sample before and after the attacks can be used for estimating $\gamma$. Therefore the model does not measure the amount of discrimination faced by newly entering, less experienced and less certified hosts and the sample is biased towards listings with high survival times. Assessing the effects of the terrorist attacks via repeated OLS thus assures a more representative sample representing the entire market, whereas assessing it via a fixed effects model eliminates worries about any omitted variable bias stemming from non-time varying characteristics.

Using the results from these estimations we proceed to calculate counterfactual revenues for Arab/Muslim hosts. We increase the observed average daily price and occupancy rate of all Arab/Muslim hosts in our sample by the percentage reflected in the repeated monthly OLS regression coefficients for having an Arab/Muslim name. Based on the counterfactual occupancy rate and monthly price we calculate a counterfactual revenue from which we derive the average monthly as well as the cumulative foregone revenue of all Arab/Muslim hosts. We identify the additional costs resulting from the November 2015 attacks based on a comparison of the average monthly loss of individual hosts before and after the month of the attacks and the amount of additional losses resulting from average discrimination being higher after the attacks. As a robustness check we use estimations from the listing fixed effects models to calculate the additional revenue loss resulting from stronger discrimination after the terrorist attacks. (see Annex Section $\mathrm{C}$ for a more detailed description)

Since we exclude listings that were not rented out in a given month in the sample used for estimating price, but not in the sample used for estimating occupancy rate, we checked the robustness of our results by redoing the occupancy rate analysis on the sample used for price estimations. 

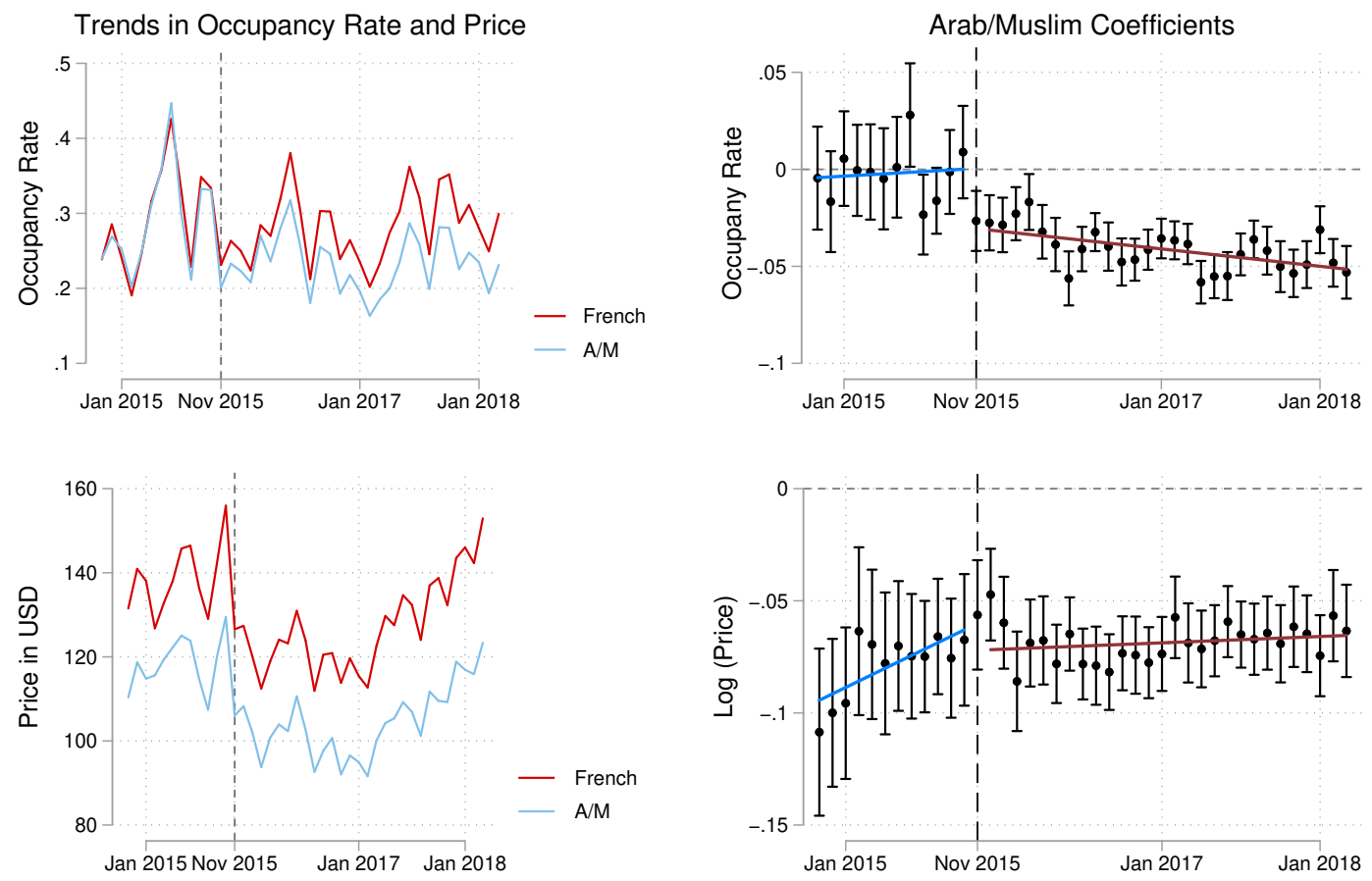

Figure 2: Left side: Average monthly occupancy rate and price for Arab/Muslim (A/M) and French listings. Right side: Coefficients for hosts with $\mathrm{A} / \mathrm{M}$ names including $95 \%$ confidence intervals from repeated monthly OLS regressions on occupancy rate and price. Models include all controls except reviews. Fitted linear prediction lines calculated separately on coefficients before and after November 2015 attacks.

\section{Results}

The first step in our analysis was to measure the overall level of discrimination against hosts with typically Arab/Muslim names via random effects panel models. With these measurements at hand, we then analyzed how discrimination evolved over time, using repeated OLS models and then looked in particular at changes around the November 2015 Paris terrorist attacks via listing fixed effects models.

The results from the random fixed effects model in Fig 1 , show economically meaningful discrimination based on ethnic/religious characteristics. For reasons of parsimony we display only select control variables (see Appendix Table 4 for full results). Overall, listings of hosts with Arab/Muslim names have lower price and occupancy levels. We find for listings of Arab/Muslim hosts a 13\% lower price level and a $4.5 \%$ lower occupancy rate. Note that the size of the coefficients is not directly comparable between models for price and occupancy rate because they measure elasticities (percentage change in price) in the first case and, in the latter, deviations from the occupancy rate, which has a sample average of $28 \%$, in absolute percentage terms. We provide an estimate of the relative effect of differences in price and occupancy rates in the section on costs at the end of the following subsection.

The above raw differences result in part from variations in the quality and location of listings. Following the introduction of controls for listing characteristics (and reviews), differences in price levels decline to a disadvantage of $6.0 \%$ (5.8\% with review controls); for occupancy rates, estimates drop to a disadvantage of $3.6 \%(3.2 \%)$ for hosts with Arab/Muslim names. In sum, we find that hosts with Arab/Muslim names incur a clear disadvantage in revenue due to both lower prices and lower occupancy rates relative to hosts with typically French names.

\section{Increases in Discrimination after November 2015 Attacks}

Having established the average amount of discrimination, we proceeded to explore whether the strength of discrimination changed over time, in particular around November 2015 when Paris was struck by a 
series of coordinated multi-site, lethal terrorist attacks. The Islamic State of Iraq and the Levant claimed responsibility and all immediate perpetrators, mostly French and Belgian citizens, appeared to be of Arab descent and Muslim confession. The events led to a logical contraction of the Airbnb market. In our data, the effect is visible in the abrupt and substantial drop in average price and occupancy rates of listings; price levels took over a year to recover to the pre-attacks levels (left side of Fig. 2). Given the symbolic associations of the attacks, a rise in discrimination against Airbnb hosts with Arab/Muslim names is an expected outcome we test for.

The historical trends of price and occupancy rate displayed on the left side of Fig. 2 2 reveal a substantive change concomitant with the month of the attacks. Prior to November 2015 there is no visible and statistically significant difference between the occupancy rates of hosts with French or Arab/Muslim names. But for every month thereafter, listings of Arab/Muslim hosts display lower rates. The effect appears to add onto differences in price levels. The trend in price rates is visibly sensitive to the attacks but the price gap of around $20 \$$ between hosts with French and Arab/Muslim names remains stable around November 2015 and throughout the entire period. The terrorist attacks appear to increase discrimination against Arab/Muslim hosts by adding a penalty on occupancy beyond and over a pre-existing price gap.

We corroborated the conclusions from the descriptive trends via repeated OLS regressions, modelling monthly price and occupancy rate separately for each month. The models measure the effect of being an Arab/Muslim host conditional on listing characteristics. We estimated models with and without listing reviews; results being broadly similar, we display the coefficients of models without controls for reviews on the right side of Fig. 2 (see Appendix Fig. 11-14 for results without any controls and with review controls). The graph displays coefficients and confidence intervals showing the effects of being a host with an Arab/Muslim name relative to a French name on price and occupancy rates in each month. Coefficients for the models with $\log$ (price) as dependent variable show fluctuations in the trend, indicating a decline in the price gap at the beginning of the time period in the last months of 2014 . The overall trend is nonetheless stable over time with an average price differential in the range of 5-8\% at the expense of Arab/Muslim hosts. The coefficients for the effect of a host having an Arab/Muslim name show no difference in occupancy rates before the month of the attacks. A persistent and stable gap opens after that point however, with Arab/Muslim hosts incurring a 2-5\% lower occupancy rate.

In an additional test of the effect of the terrorist attacks we estimated models with listing fixed effects, displayed in table 2 (full results are in Appendix Table 7). The advantage of these models is that all unobserved non-time varying characteristics do not influence our estimates, nor do any differences in listing characteristics of hosts who enter the market after November 2015. The disadvantage is that we cannot estimate the overall level of discrimination against Arab/Muslim hosts, since the ethnic/religious affiliation of host names is a time-invariant characteristic. As discussed in the methods section, we do however model the change in strength of discrimination before and after the attacks. The parameter identifying this change is calculated on a smaller sample of hosts with higher survival times and better certification. This is because listings had to be present in the data before and after the attacks to identify the influence of host characteristics on changes in price and occupancy rates within individual listings. This also means that new market entrants after the November 2015, and them being potentially treated differently, is not captured by these models. This notwithstanding, the fixed effects models show a significant drop in occupancy rates for Arab/Muslim hosts (2.3\%) after the attacks, with the effect size being only slightly smaller than in the repeated OLS models. Additionally, and in contrast to the repeated OLS regressions, the listing fixed effects approach shows a $1.8 \%$ higher price penalty for Arab/Muslim hosts after the terrorist attacks. In spite of this difference, the two modelling approaches yield a consistent picture of the rise in discrimination against hosts with Arab/Muslim names following the attacks. Specifically, in our subsequent estimation of monetary losses associated with the rise in discrimination after November 2015, the results from both approaches arrive at cost estimates in a comparable range and both identify the decline in occupancy rates among Arab/Muslim listings as the main driver (around two-thirds) of rising costs for hosts with Arab/Muslim names (see Appendix Table 10).

\section{Calculating Revenue Loss}

Based on our results we provide estimates of how much revenue hosts with Arab/Muslim names lost due to observed differences in price and occupancy rates. These estimates give an intuitive, monetary measure of the effect of discrimination as well as a unit for comparing the contribution of price and occupancy rate differences to lowering the revenue of minority hosts. We calculated counterfactual scenarios for the addi- 
Table 2: Estimates From Listing Fixed-Effects Regressions

\begin{tabular}{|c|c|c|c|c|c|c|}
\hline & \multicolumn{3}{|c|}{ Occupancy Rate } & \multicolumn{3}{|c|}{$\log ($ Price $)$} \\
\hline & (1) & (2) & (3) & (1) & (2) & (3) \\
\hline Post Attacks & $\begin{array}{c}0.000229 \\
(0.26)\end{array}$ & $\begin{array}{c}-0.0125^{\text {*** }} \\
(-13.82)\end{array}$ & $\begin{array}{c}-0.0376^{* * *} \\
(-34.78)\end{array}$ & $\begin{array}{c}-0.0268^{* * *} \\
(-39.92)\end{array}$ & $\begin{array}{c}-0.0339^{* * *} \\
(-49.26)\end{array}$ & $\begin{array}{c}-0.0665^{* * *} \\
(-87.16)\end{array}$ \\
\hline A/M $*$ Post Attacks & $\begin{array}{c}-0.0195^{* * *} \\
(-5.97)\end{array}$ & $\begin{array}{c}-0.0228^{* * *} \\
(-7.01)\end{array}$ & $\begin{array}{c}-0.0261^{* * *} \\
(-7.24)\end{array}$ & $\begin{array}{c}-0.0171^{* * *} \\
(-6.69)\end{array}$ & $\begin{array}{c}-0.0184^{* * *} \\
(-7.21)\end{array}$ & $\begin{array}{c}-0.0227^{* * *} \\
(-9.01)\end{array}$ \\
\hline Listing Characteristics & & $\mathrm{x}$ & $\mathrm{x}$ & & $\mathrm{x}$ & $\mathrm{x}$ \\
\hline Reviews & & & $\mathrm{x}$ & & & $\mathrm{x}$ \\
\hline Observations & 1026416 & 1026416 & 839390 & 514702 & 514702 & 480427 \\
\hline Listings & 72981 & 72981 & 54175 & 65280 & 65280 & 52390 \\
\hline$R^{2}$ & 0.00186 & 0.0650 & 0.0803 & 0.00904 & 0.185 & 0.0449 \\
\hline
\end{tabular}

tional amount of revenue that listings would have received under the assumption that differences in price and/or occupancy rates for hosts with Arab/Muslim names are null, after controlling for listing characteristics. More precisely, we inferred the potential gains for price and occupancy rates from the coefficients for having an Arab/Muslim name in repeated monthly OLS regression models with controls for listing characteristics. The sample of analysis includes listings for which there are observations for monthly price - a necessary condition to estimate counterfactual prices (see Appendix section C for details on the modelling approach and Appendix Tables 9 and Table 10 for additional results). In Table 3 we report observed average monthly revenue of Arab/Muslim and French listings along with estimates for average monthly revenue gains for hosts with Arab/Muslim names under three scenarios of absence of differences: in occupancy rates only, in price only, and in both. We report results for the entire sample and for the sub-samples of observations before $(11 / 2014$ - 10/2015) and after (12/2015 - 03/2018) the terrorist attacks.

On average the observed revenue of listings of hosts with French names is 1.713 \$ US, while that of hosts with Arab/Muslim names is 1.392 \$, resulting in a difference of 321 \$. Following controls for listing characteristics, the difference drops to 208 \$ (169 \$ with review controls). Differences in price and occupancy rates contribute almost equal parts to observed differences in revenue between hosts with French and Arab/Muslim names. Note that the revenue gains under the scenarios modelling counterfactual occupancy rate and price separately do not add up to the value of the scenario which models them jointly because a higher occupancy rate yields even greater returns if price is higher and vice versa.

A comparison of the estimates for two sub-samples of observations, one prior and the other following the terrorist attacks of November 2015, illustrates how discrimination changed in size and substance. For one, we can note that it increased overall as we find an increase in the differences in observed average monthly revenues for French and Arab/Muslim listings. Average monthly revenue for hosts with Arab/Muslim names declined from 1502 \$ before the attacks to 1383 \$ after, while it increased from 1603 \$ to 1738 \$ for those with French names. Similarly, after controlling for listing characteristics we find that the revenue difference attributable to having Arab/Muslim names increased from 121 \$ (106 \$ with review controls) prior to the attacks to $220 \$(178 \$$ ) thereafter. Second, discrimination changed in substance. Price differences accounted almost entirely for estimated revenue losses in Arab/Muslim listings before November 2015. After this month, the effect of differences in occupancy rates overcomes, by a substantial margin, the contribution of price differences to discrimination against hosts with Arab/Muslim names.

In addition, we provide estimates of the overall market revenue forgone on Arab/Muslim listings. We estimate that the revenue lost across all hosts of Arab/Muslim listings ranged from 5.5 million \$ (model with review controls) to 6.2 million $\$$ (without review controls). Absent any differences in price and occupancy rates, this would have corresponded to a $10 \%$ increase in the total revenue that Arab/Muslim hosts collected between November 2014 and March 2018. Absent differences in price only, the result would have been an additional revenue of 3.5-3.6 million \$. Absent differences in occupancy rates only, this number would have amounted to 2.3-2.9 million $\$$ of additional revenue. 


\begin{tabular}{|c|c|c|c|c|c|c|c|c|c|}
\hline & \multicolumn{3}{|c|}{ Overall } & \multicolumn{3}{|c|}{ Pre-Attack } & \multicolumn{3}{|c|}{ Post-Attack } \\
\hline & Calc & Ctrls & Ctrls \& Revs & Calc & Ctrls & Ctrls \& Revs & Calc & Ctrls & Ctrls \& Revs \\
\hline Revenue $(\mathrm{A} / \mathrm{M})$ in $\$$ & $1,392.69$ & & & $1,501.67$ & & & $1,383.27$ & & \\
\hline Revenue (French) in \$ & $1,713.34$ & & & $1,603.01$ & & & $1,737.81$ & & \\
\hline Add. Revenue (AM) w/o OR Diff \$ & & 104.28 & 83.54 & & 6.31 & 2.97 & & 117.05 & 93.94 \\
\hline Add. Revenue (AM) w/o Price Diff \$ & & 96.55 & 81.22 & & 114.20 & 102.51 & & 94.87 & 78.87 \\
\hline Add. Revenue (AM) w/o OR \& Price Diff \$ & & 207.97 & 169.48 & & 121.04 & 105.72 & & 219.93 & 178.11 \\
\hline
\end{tabular}

Table 3: Average monthly revenue of listings and additional revenue of hosts with Arab/Muslim (A/M) names under the assumption that occupancy rate (OR) and/or price differences associated with ethnic/religious origin of host name do not exist. Calculations for entire sample and separately for sample of observations prior and post November 2015

\section{Conclusion}

In this study we focused on an emblematic market place of the sharing economy and its sensitivity to terrorist attacks. Like researchers before us (Edelman et al., 2017, Edelman and Luca, 2014; Laouénan and Rathelot, 2017), we found evidence of substantive day-to-day discrimination against a traditionally disadvantaged ethno-religious minority - individuals with Arab/Muslim names advertising properties for rent on Airbnb's market in Paris. Already high, the penalties increased following the deadly terrorist attacks of November 2015. Adding onto a prior price disadvantage, Arab/Muslim hosts incurred a penalty in occupancy whose rate began declining relative to hosts with typically French names only after the month of the attacks and lingered for almost two and a half years, up to March 2018 (our last data point).

Notwithstanding the idiosyncrasy of the tragic events of November 2015, the size of the rental market in Paris renders these findings emblematic of the potential influence of mass terrorism. Large competitive markets are expected to price out discrimination over time and to recover quicker from exogenous shocks. Our 41-month long stretch of data on Airbnb's largest metropolitan market illustrates the limits of market forces to curb discrimination over time and their susceptibility to the potential of terrorism to amplify prejudices in economic decisions by private individuals. Furthermore, economic theory, under the assumption that markets adjust to equilibrium instantaneously, would have predicted changes in discriminatory patterns to be directly observable in price differences. We detected changes in occupancy rates instead. This illustrates the importance of observing a broader range of outcomes to fully capture discriminatory practices. In this respect, the sharing economy acts as a precious and rich source for real-time data collection to monitor the substance and evolution of discriminatory practices.

The analysis of discrimination with observational data like ours is subject to omitted variable bias. In our particular case this may result from missing data on the content of visuals and on written descriptions of Airbnb properties as well as from any unobserved micro-level neighbourhood differences, each of which, if correlated with host ethnicity, may bias model estimates. This possibility notwithstanding, our findings on changes in discrimination after the attacks are less susceptible to omitted variable bias. The repeated monthly OLS regression models, which yielded the estimates for change in discrimination after November 2015 , relied on the assumption that unobserved non-time varying characteristics as well as any differences in listing characteristics of hosts entering the market following the month of the attacks did not influence our estimates. The Airbnb market is logically dynamic both with regard to new entries and to the evolution of individual listings. We therefore complemented the models with a fixed effects approach which relaxed the above assumption and yielded broadly similar results.

In conclusion, our analysis complemented past findings on the persistence and intensity of day-to-day discrimination in online peer-to-peer markets and showed evidence on their sensitivity to terrorist attacks. Neither of these is an exclusive feature of the sharing economy. Evidence of discrimination in the traditional economy is aplenty (Pager and Shepherd, 2008, Quillian et al., 2017, Adida et al., 2010) and not lacking with regard to the effects of terrorism (Gautier et al., 2009; Dávila and Mora, 2005; Kaushal et al., 2007, Glover. 2019, Ratcliffe and von Hinke, 2015). But as the sharing economy and its characteristic reliance on revealed personal information of buyers and sellers has grown to become an essential feature of contemporary economies, our findings invite further scrutiny on these new markets by researchers and policy makers willing to understand the specific mechanisms of discrimination and to limit its consequences. 


\section{References}

Abrahao, B., Parigi, P., Gupta, A., and Cook, K. S. (2017). Reputation offsets trust judgments based on social biases among Airbnb users. Proceedings of the National Academy of Sciences, 114(37):98489853.

Acolin, A., Bostic, R., and Painter, G. (2016). A field study of rental market discrimination across origins in france. Journal of Urban Economics, 95(C):49-63.

Adida, C. L., Laitin, D. D., and Valfort, M.-A. (2010). Identifying barriers to Muslim integration in France. Proceedings of the National Academy of Sciences, 107(52):22384-22390.

Aubry, B. and Tribalat, M. (2011). Les concentrations ethniques en France : évolution 1968-2005. Espace populations sociétés, 3:493-507.

Ayres, I., Banaji, M., and Jolls, C. (2015). Race effects on eBay. The RAND Journal of Economics, 46(4):891-917.

Bail, C. A. (2012). The fringe effect: Civil society organizations and the evolution of media discourse about islam since the september 11th attacks. American Sociological Review, 77(6):855-879.

Beauchemin, C., Hamel, C., and Simon, P. (2016). Trajectoires et Origines: Enquête sur la Diversité des Populations en France. INED Editions.

Behaghel, L., Crépon, B., and Le Barbanchon, T. (2015). Unintended effects of anonymous résumés. American Economic Journal: Applied Economics, 7(3):1-27.

Braakmann, N. (2009). The Impact of September 11th, 2001 on the Employment Prospects of Arabs and Muslims in the German Labor Market. Journal of Economics and Statistics (Jahrbuecher fuer Nationaloekonomie und Statistik), 229(1):2-21.

Braakmann, N. (2010). Islamistic terror and the labour market prospects of arab men in england: Does a country's direct involvement matter? Scottish Journal of Political Economy, 57(4):430-454.

Bunel, M., l'Horty, Y., Mbaye, S., Parquet, L. D., and Petit, P. (2018). Vous ne dormirez pas chez moi ! Tester la discrimination dans l'hébergement touristique. Working Papers halshs-01878182, HAL.

Bunel, M., l'Horty, Y., Parquet, L. D., and Petit, P. (2017). Les Discriminations Dans L'Acces Au Logement A Paris : Une Experience Controlee. Working Papers halshs-01521995, HAL.

Calo, R. and Rosenblat, A. (2017). The taking economy: Uber, information, and power. Columbia Law Review, 117:1623-1690.

Cui, R., Li, J., and Zhang, D. (2016). Discrimination with incomplete information in the sharing economy: Evidence from field experiments on Airbnb. SSRN Electronic Journal, pages 1-38.

Diekmann, A., Jann, B., Przepiorka, W., and Wehrli, S. (2014). Reputation formation and the evolution of cooperation in anonymous online markets. American Sociological Review, 79(1):65-85.

Doleac, J. and Stein, L. (2013). The visible hand: Race and online market outcomes. Economic Journal, 123(11):F469-F492.

Dávila, A. and Mora, M. T. (2005). Changes in the earnings of Arab Men in the US between 2000 and 2002. Journal of Population Economics, 18(4):587-601.

Echebarria-Echabe, A. and Fernández-Guede, E. (2006). Effects of terrorism on attitudes and ideological orientation. European Journal of Social Psychology, 36(2):259-265.

Edelman, B. and Luca, M. (2014). Digital discrimination: The case of Airbnb.com. Harvard Business School Working Papers 14-054, Harvard Business School.

Edelman, B., Luca, M., and Svirsky, D. (2017). Racial discrimination in the sharing economy: Evidence from a field experiment. American Economic Journal: Applied Economics, 9(2):1-22. 
Finseraas, H. and Listhaug, O. (2013). It can happen here: The impact of the Mumbai terror attacks on public opinion in Western Europe. Public Choice, 156(1):213-228.

Flage, A. (2018). Ethnic and gender discrimination in the rental housing market: Evidence from a metaanalysis of correspondence tests, 2006-2017. Journal of Housing Economics, 41(C):251-273.

Gaddis, S. M. (2017). How black are Lakisha and Jamal? Racial perceptions from names used in correspondence audit studies. Sociological Science, 4(19):469-489.

Garcia, D. and Rimé, B. (2019). Collective emotions and social resilience in the digital traces after a terrorist attack. Psychological Science, 30(4):617-628. PMID: 30865565.

Gautier, P. A., Siegmann, A., and Van Vuuren, A. (2009). Terrorism and attitudes towards minorities: The effect of the Theo van Gogh murder on house prices in Amsterdam. Journal of Urban Economics, 65(2):113-126.

Ge, Y., Knittel, C. R., MacKenzie, D., and Zoepf, S. (2016). Racial and gender discrimination in transportation network companies. NBER Working Papers 22776, National Bureau of Economic Research, Inc.

Gigerenzer, G. (2006). Out of the frying pan into the fire: behavioral reactions to terrorist attacks. Risk Analysis, 26(2):347-351.

Glover, D. (2019). Job search and intermediation under discrimination: Evidence from terrorist attacks in France. Chaire SPP Working Paper 2019-02.

Goel, D. (2010). Perceptions of immigrants in australia after 9/11*. Economic Record, 86(275):596-608.

Hersh, E. D. (2013). Long-term effect of September 11 on the political behavior of victims' families and neighbors. Proceedings of the National Academy of Sciences, 110(52):20959-20963.

Hopkins, D. J. (2010). Politicized places: Explaining where and when immigrants provoke local opposition. The American Political Science Review, 104(1):40-60.

Kakar, V., Voelz, J., Wu, J., and Franco, J. (2018). The visible host: Does race guide Airbnb rental rates in San Francisco? Journal of Housing Economics, 40(C):25-40.

Kaushal, N., Kaestner, R., and Reimers, C. (2007). Labor market effects of September 11th on Arab and Muslim residents of the United States. The Journal of Human Resources, 42(2):275-308.

Laouénan, M. and Rathelot, R. (2017). Ethnic discrimination on an online marketplace of vacation rental. Université Paris1 Panthéon-Sorbonne (Post-Print and Working Papers) hal-01514713, HAL.

Le Gallo, J., L'Horty, Y., Du Parquet, L., and Petit, P. (2018). Les discriminations dans l'accès au logement en France : un testing de couverture nationale. Working Papers halshs-01878188, HAL.

Legewie, J. (2013). Terrorist events and attitudes toward immigrants: A natural experiment. American Journal of Sociology, 118(5):1199-1245.

Leong, N. and Belzer, A. (2017). The new public accommodations: Race discrimination in the platform economy. 105 Georgetown Law Journal, 1271.

Massey, D. S. (2005). Racial discrimination in housing: A moving target. Social Problems, 52(2):148-151.

Montalvo, J. G. (2011). Voting after the bombings: A natural experiment on the effect of terrorist attacks on democratic elections. The Review of Economics and Statistics, 93(4):1146-1154.

Nunley, J. M., Owens, M. F., and Howard, R. S. (2011). The effects of information and competition on racial discrimination: Evidence from a field experiment. Journal of Economic Behavior \& Organization, 80(3):670-679.

Pager, D. and Shepherd, H. (2008). The sociology of discrimination: Racial discrimination in employment, housing, credit, and consumer markets. Annual Review of Sociology, 34(1):181-209. 
Quillian, L., Pager, D., Hexel, O., and Midtbøen, A. H. (2017). Meta-analysis of field experiments shows no change in racial discrimination in hiring over time. Proceedings of the National Academy of Sciences, 114(41):10870-10875.

Rabby, F. and Rodgers, W. (2011). Post 9-11 u.s. muslim labor market outcomes. Atlantic Economic Journal, 39(3):273-289.

Ratcliffe, A. and von Hinke, S. (2015). The London bombings and racial prejudice: Evidence from the housing and labor market. Economic Inquiry, 53(1):276-293.

Rich, J. (2014). What do field experiments of discrimination in markets tell us? A meta analysis of studies conducted since 2000. IZA Discussion Papers 8584, Institute for the Study of Labor (IZA).

Schüller, S. (2016). The effects of $9 / 11$ on attitudes toward immigration and the moderating role of education. Kyklos, 69(4):604-632.

Sheridan, L. P. (2006). Islamophobia pre- and post-september 11th, 2001. Journal of Interpersonal Violence, 21(3):317-336. PMID: 16443594.

Silver, R. C., Holman, E. A., McIntosh, D. N., Poulin, M., and Gil-Rivas, V. (2002). Nationwide Longitudinal Study of Psychological Responses to September 11. JAMA, 288(10):1235-1244.

Spilerman, S. and Stecklov, G. (2009). Societal responses to terrorist attacks. Annual Review of Sociology, 35(1):167-189.

Tjaden, J. D., Schwemmer, C., and Khadjavi, M. (2018). Ride with Me-Ethnic Discrimination, Social Markets, and the Sharing Economy. European Sociological Review, 34(4):418-432.

Todisco, M. (2015). Share and share alike? Considering racial discrimination in the nascent room-sharing economy. Stanford Law Review Online, 67:121-129.

Tribalat, M. (2015). An estimation of the foreign-origin populations of France in 2011. Espace Populations Sociétés, 2015/1-2.

Wang, C. (2018). The impact of 9/11 on the self-employment outcomes of arab and muslim immigrants. International Migration Review, 52(2):430-457.

Åslund, O. and Rooth, D.-O. (2005). Shifts in attitudes and labor market discrimination: Swedish experiences after 9-11. Journal of Population Economics, 18(4):603-629. 


\section{Appendix}

\section{A Supplementary Airbnb Listing Variable Information}

Instantbooking means that a listing can be rented out without asking/contacting the host in advance. Superhost is a status given to hosts by Airbnb if they have an overall rating above 4.8, at least 10 visits within the last year, or at least 100 nights and 3 visits, 0 cancellations and a response rate of $90 \%$ within 24 hours to messages sent to them by guests. Business ready is a certification given to listings, which provide a given list of amenities ranging from wireless internet and a laptop friendly work-space to such things as smoke detectors and shampoo, towels and hair dryers. Business ready hosts must also have at least 5 stars for $60 \%$ of their overall, cleanliness and accuracy reviews, propose an entire home for rent and respond to $90 \%$ of guest requests within 24 hours.

\section{B Additional Results and Robustness Checks}

First we provide some additional information on our spatial controls. As noted neighborhood variables are used to control for the spatial distribution of listings. Using geocoded information on the listings we divided the city into 81 neighborhood zones which we use as dummy controls. We further assigned listings to 13 designated tourist zones as published by the Mairie de Paris (Paris City Hall) on their Open Data website, which overlap with the 81 neighborhood zones. We included each of these tourist zones as additional dummy control variables for spatial effects. Fig 3 displays the 81 Airbnb districts in grey and the 13 tourist zones in blue. Fig 4 shows variation in prices across the 81 neighborhood zones designated by Airbnb, which we use as neighborhood controls $N_{i}$. Fig 5 presents the distribution across the 81 zones of hosts with Arab/Muslim names. It illustrates their under-representation in the central districts of Paris.

We also provide additional descriptive statistics to better understand the development of the Airbnb market in Paris. Fig. 6 shows the number of active listings in our sample for each month. There was no notable effect of the November 2015 terrorist attacks on the upward trend in the number of listings. The share of listings with hosts having Arab/Muslim names increased over the observed time period from 7\% in November 2014 to $9 \%$ in March 2018. Fig. 7 shows the percentage of listings exiting the market. We defined exit as the last month a listing was available for rental before disappearing from the website without returning at a later date. We find a drop in exits shortly before the November 2015 attacks, for which we have no coherent explanation, and an uptick after them. Changes in exits and differences in exit rates between French and Arab/Muslim host listings yield no consistent story of an effect of the attacks.

Since we displayed price levels in the main text for illustrative purposes, Fig. 8 shows the trend in $\log$ (price) which is the dependent variable we use in our regression models on price.

The monthly revenue of a host is the product of the occupancy rate, the number of days a listing was available and the average monthly price. We model occupancy rate and price in our paper since they are the variables most directly linked to discriminatory behavior. Fig. 9 shows the average number of days listings of Arab/Muslim and French hosts were made available in each month. Three things stand out: 1) Arab/Muslim hosts consistently make their listings available for more days than French hosts; 2) hosts react to the November 2015 attacks by making their listings available for more days; 3) the difference between French and Arab/Muslim hosts in the number of days listed is reduced after the attacks. Fig. 10 shows trends in monthly revenue. Prior to the attacks Arab/Muslim hosts and French hosts have very similar monthly revenues, with Arab/Muslim hosts making up for lower prices by having their listings available for more days. After the attacks a clear gap in revenue emerges.

Table 4 displays estimates of the random effects model, which we used to obtain the Fig. 1. Variables for the number of reviews and photos were divided by ten for easier display of coefficients. We implemented the same setup of random effects models using monthly price in US \$ (taken in levels instead of logs) and monthly revenue as dependent variables. The results can be seen in Table 5 We generally do not use revenue as the dependent variable as it depends on the number of days listings were made available, which is a variable more dependent on host preferences than consumer discrimination (even though it might also react to discriminatory patterns). All models show a penalty of at least $8 \$$ on average daily price and a 
monthly revenue penalty of at least $110 \$$ for male and female hosts with Arab/Muslim names compared with French male hosts.

Since we exclude listings that were not rented out in a given month in the sample used for estimating price, but not in the sample used for estimating occupancy rate, we checked the robustness of our results by redoing the occupancy rate analysis on the sample used for price estimations. Results can be found in Tab. 6. Overall, results are very similar.

We also estimated additional versions of the repeated monthly OLS models. While in the main text results for log price and occupancy rate, from the models with listing controls and without review controls are displayed, the monthly raw differences from models without any controls, are found in Fig 11 and Fig 12 The models including listing and review controls can be seen in Fig 13 and Fig 14 They show slightly weaker overall discrimination but a similar break in occupancy rates occurring after the November 2015 attacks.

We also estimated repeated OLS models taking revenue as the dependent variable. Fig. 15 shows results from the model controlling for listing characteristics and Fig. 16 from the model controlling for listing characteristics and reviews. They confirm that the marked drop in occupancy rates for Arab/Muslim hosts resulted in significantly lower revenues after the November 2015 attacks.

\section{Calculation of Monetary Losses}

To assess the monetary consequences of the observed discriminatory patterns we construct counterfactual scenarios. We calculate the additional amount of money Arab/Muslim listings would have made under the assumption that price differences associated with the ethnic/religious origin of host name do not exist.

Monthly Revenue rev $_{l t}$ in month $t$ for listing $l$ is calculated by multiplying the number of days a listing was available $d_{l t}$ with its occupancy rate $o_{l t}$ and the average daily price rate for that month $p_{l t}: \operatorname{rev}_{l t}=$ $p_{l t} * o_{l t} * d_{l t}$.

The first column of Table 3 shows the average monthly revenue as well as the total revenue of all Arab/Muslim and French listings in our sample. Reported values are for a sample, which excludes monthly observations of listings that were not rented out in a given month. The reason for this sample selection is that we cannot calculate a counterfactual price for these listings. This explains the higher average monthly revenues, compared to those reported in Table 1, which includes revenues of zero for listings that were available for rental but not rented out.

Total revenue for all our listings $l$ in the 41 months $t$ we observe is calculated as rev $v^{\text {tot }}=\sum_{l, t}$ rev $_{l t}$. Average monthly revenue is defined as $\mathrm{rev}^{\mathrm{avg}}=\frac{\mathrm{rev}_{\mathrm{t}}^{\mathrm{tot}}}{\sum_{\mathrm{t}}}$ where $\# l_{t}$ is the number of active listings in month $t$. More intuitively expressed, we calculate the average revenue across all monthly sample observations. The total revenue of all French host listings in our sample between November 2014 and March 2018 was 818 million \$ and that of Arab/Muslim hosts was 63 million \$. The average monthly revenue of a French host listing was 1713 \$ per month and that of an Arab/Muslim listing 1392 \$.

We then proceed to calculate counterfactual revenues for Arab/Muslim hosts. Our first step is to use the coefficients from the repeated monthly OLS models (2), including controls but no reviews, and (3), including controls and reviews, to calculate counterfactual occupancy rates and prices. Recall that coefficients $\beta_{t}$ tell us the effect of being an Arab/Muslim host relative to being a French host on price and occupancy rate in a given month. We calculate the counterfactual occupancy rate as $o \tilde{r}_{l t}=o r_{l t}-\beta_{t, o r}$ and the counterfactual price as $\tilde{p_{l t}}=p_{l t} *\left(1-\beta_{t, p}\right)$. The differences in the method of calculation stem from the fact that our price coefficients capture elasticities whereas those for occupancy rate capture changes in percentage levels. We use the resulting values to calculate a counterfactual revenue for each month for the Arab/Muslim host population: $r \tilde{e} \tilde{v}_{l t}=\tilde{p_{l t}} * \tilde{o_{l t}} * d_{l t}$, where $d_{l t}$ are the number of days the listing was available. To separately assess the monetary cost resulting from price and occupancy rate differences we also calculate the counterfactual revenue using only counterfactual price $\left(\tilde{p_{l t}} * o_{l t} * d_{l t}\right)$ or only counterfactual occupancy rate $\left(p_{l t} * \tilde{o_{l t}} * d_{l t}\right)$. We then proceed to calculate the foregone gains in revenue via revgain $=r e \tilde{v}_{l t}-r e v_{l t}$.

Table 1 in the main text shows the average foregone monthly revenue gains of Arab/Muslim hosts calculated for the entire sample, the sub-sample including only observations prior to the November 2015 attacks and the sub-sample of observations after the attacks. We obtain that revenue would have been between $169 \$$ (with review controls) and $208 \$$ (without review controls) higher per month if the differences we measure on occupancy rate and price were absent. The foregone revenue prior to the attacks ranges 
between $106 \$$ (with review controls) and $121 \$$ (no review controls) and is much lower than that after the attacks, which ranges between $178 \$$ (with review controls) and $220 \$$ (no review controls).

Differences in revenue between French and Arab/Muslim hosts are the result of three sets of factors: 1) the better quality of listings of French hosts which in turn have higher predicted price and occupancy rate on average; 2) the higher number of days listings of Arab/Muslim hosts are listed as available compared to those of French hosts which leads to higher revenue for Arab/Muslim hosts; and 3) the price and occupancy rate difference between Arab/Muslim and French hosts after controlling for listing characteristics (and reviews) which we interpret as a consequence of discrimination. Table 1 in the main text reports the average revenue differences and how much they would have changed if we were to correct for discrimination. In order to account for differences in the number of days listings were made available, we report Table 9 average revenue similar to that in Table 1 in the main text but here reported values are per day listed rather than per month. Note that monthly revenue net of discrimination is similar for Arab/Muslim hosts and French hosts prior to the attacks but there remain significant differences in revenue per listing day. This is due to the higher number of days Arab/Muslim hosts made listings available. In addition to revenue differences per day listed, Table 9 also includes the total of lost revenue summed over all listings and over all 41 months of observations. It ranges between 7.7 million \$ (review controls) and 9.5 million \$ (no review controls).

Finally Table 10 presents results from two alternative approaches we use to measure the cost of additional discrimination associated with the November 2015 terrorist attacks. In the first approach, instead of estimating repeated OLS regression models on a monthly basis, we estimate one OLS regression in which we compare the level of discrimination in every month after November 2015 to the average level of discrimination that we observe over the entire period before November 2015. For the purpose, we exclude observations from November 2015, use the period prior to the attacks as our reference period and include monthly dummy variables $m_{t}^{p}$ for all months after the attacks. We also control for the host having an Arab/Muslim name with $H_{i}$ and then interact hosts having an Arab/Muslim name with the set of monthly dummies for months after the attacks:

$$
y_{i t}=\alpha+\beta H_{i}+\beta_{t}^{p} H_{i} * m_{t}^{p}+\gamma N_{i}+\delta_{1} L_{i}+\delta_{2} \gamma l_{i t}+\zeta r_{i t}+\eta_{t} d_{t}^{p}+v_{i t}
$$

The coefficients $\beta_{t}^{p}$ illustrate how much stronger differences in price or in occupancy rate associated with the host having an Arab/Muslim name were in each month $t$ after the attacks compared to the average effect of having an Arab/Muslim name prior to the attacks. We use the $\beta_{t}^{p}$ coefficients from the models to calculate foregone revenue for Arab/Muslim hosts in the sub-sample of observations for the period between December 2015 and March 2018. The results illustrate how much additional revenue was foregone due to the higher post-attacks penalty for being an Arab/Muslim host. It ranges from $85 \$$ (controls with reviews) to $110 \$$ (controls without reviews) per month per Arab/Muslim listing. This corresponds to a total revenue loss of 3.4 million $\$$ (controls with reviews) or 4.4 million \$ (controls without reviews). Almost the entirety of this additional loss is explained by the increase in occupancy rate differences between Arab/Muslim and French listings.

In the second modelling approach, we calculate the effect of the terrorist attacks on revenue using the estimates from the fixed effects models. As a caveat, recall that in the fixed effects models we estimate the coefficients for changes in discriminatory patterns on a sub-sample of listings for which there are observations prior to and after the terrorist attacks. The advantage of this estimation is that estimates are not affected by unobserved time-invariant listing characteristics. Here we make use of the models' $\gamma$ coefficients which are estimates of the interaction variable $A / M *$ PostAttacks, in other words, they capture the increase in discrimination following the month of the attacks. We use them to calculate counterfactual revenues for Arab/Muslim listings after November 2015. The associated coefficients are reported in Table 77. The values for revenue loss are similar to those obtained by the calculation with coefficients from the repeated OLS regression models. Monthly revenue lost due to stronger discrimination after the attacks is $89.24 \$$ per listing per month (with controls and no reviews) or 104.73\$ (with controls and reviews). The total sum of all revenue lost in that period is estimated at 3.6 million $\$$ (with controls and no reviews) or 4.2 million $\$$ (with controls and reviews). The amount of overall foregone revenue due to the attacks is comparable between the repeated OLS models and the fixed effects models. However, in the results from the repeated OLS models the entire additional revenue loss results from changes in occupancy rates, whereas in the fixed effects approach about 3/4 of the additional revenue loss is due to changes in occupancy rate and 1/4 is due to changes in price. 


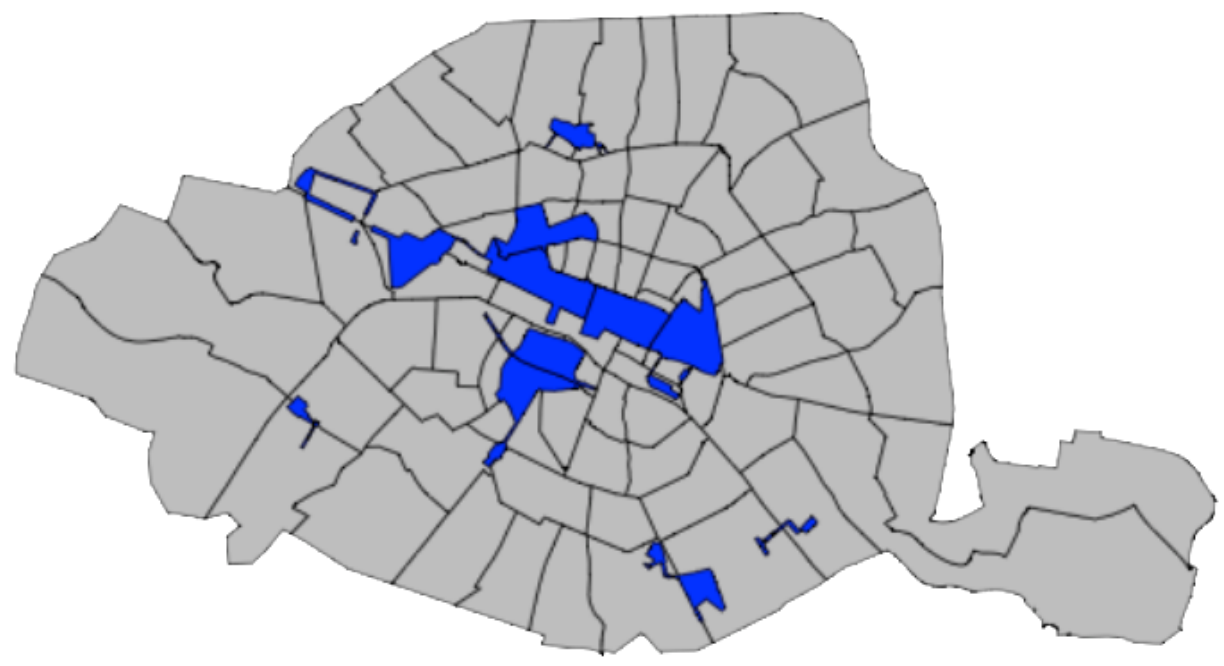

Figure 3: In Blue: 13 Tourist Zones as Designated by the Open Data Site of the Mairie de Paris. In Grey: 81 District Zones. 


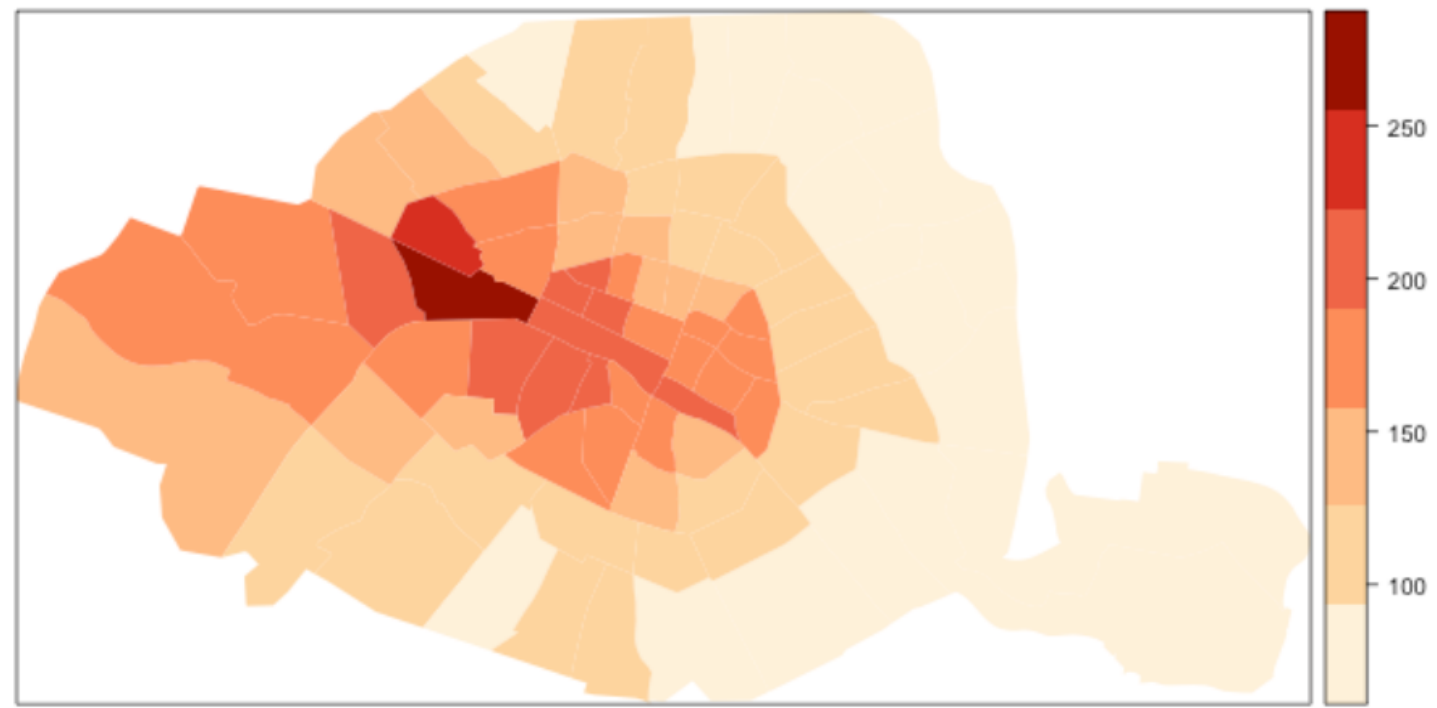

Figure 4: Average Monthly Price of All Listings March 2014 - November 2018 in USD by Neighborhood Zone 


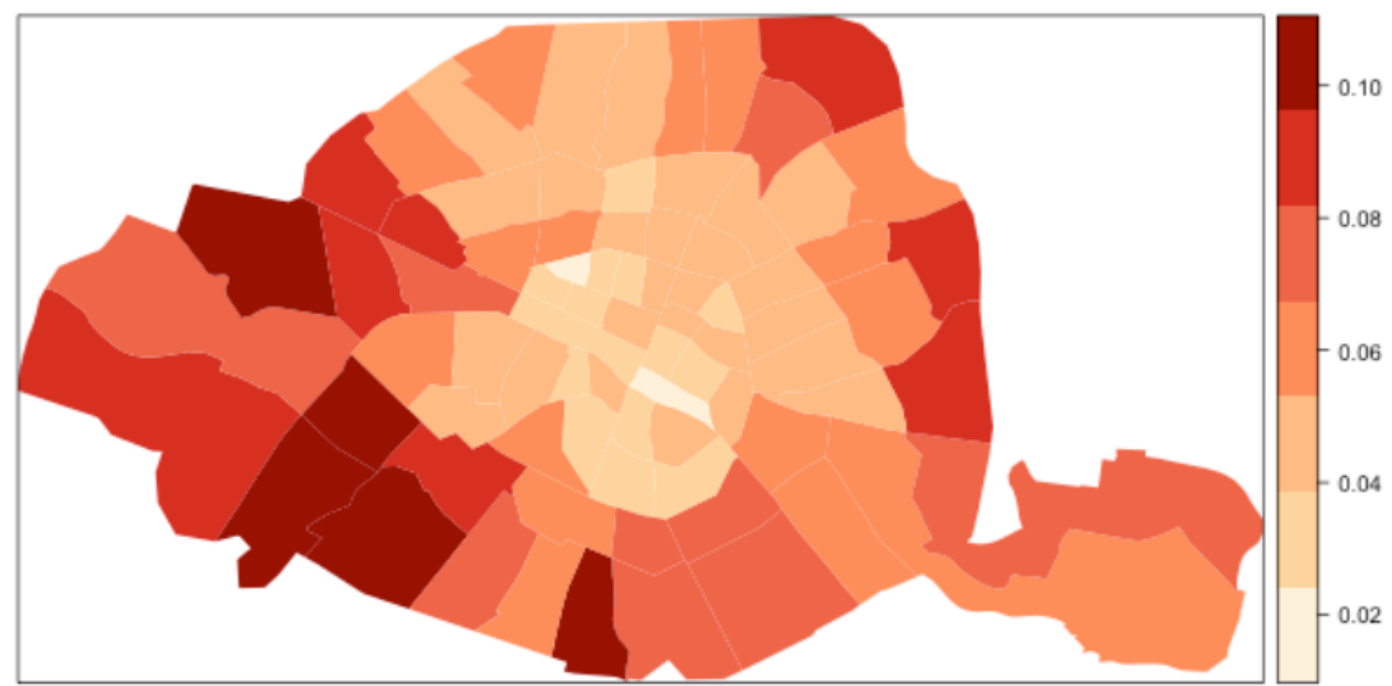

Figure 5: Percentage of Hosts with Arab/Muslim Names for All Listings March 2014 - November 2018 by Neighborhood Zone

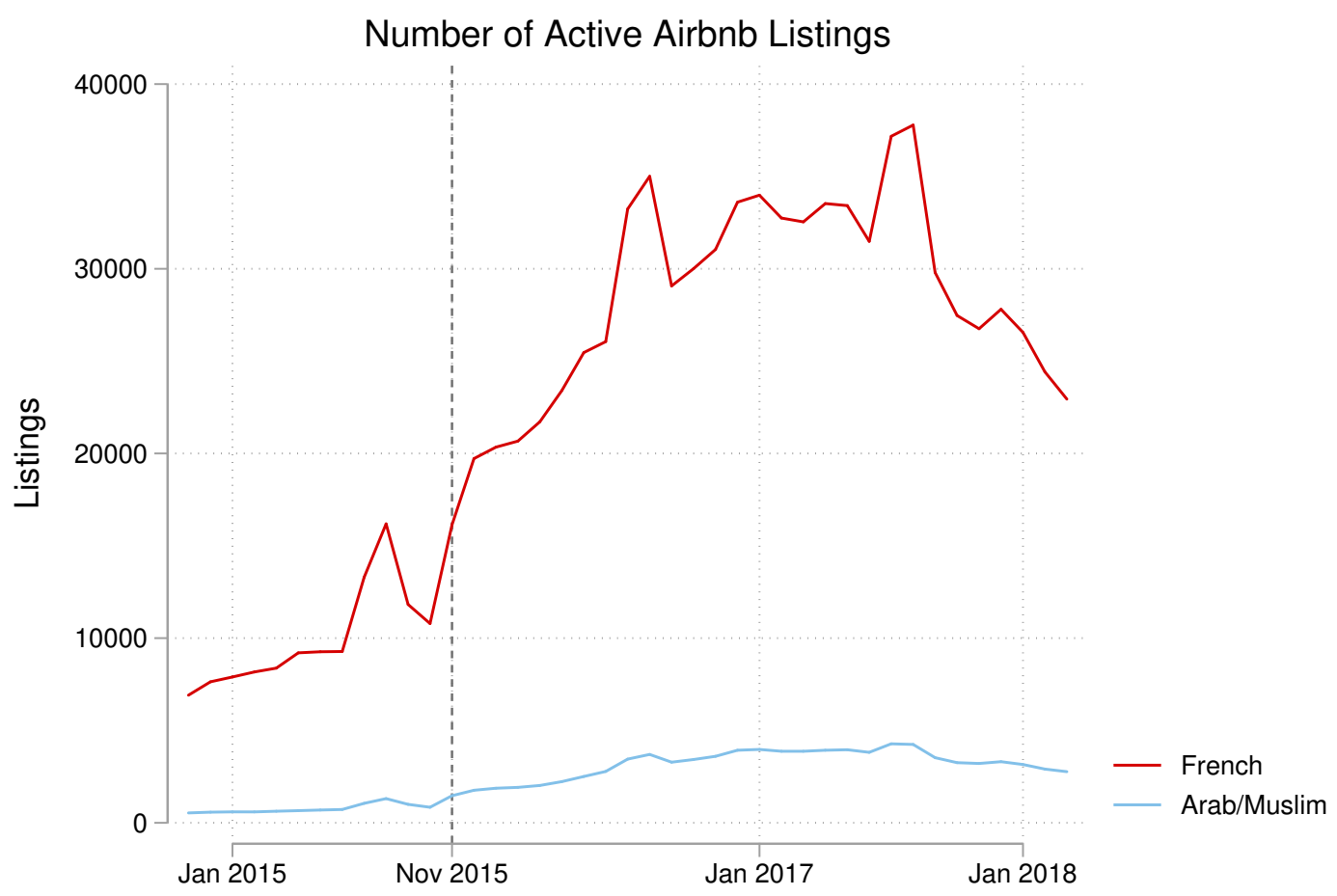

Figure 6: Number of French and Arab/Muslim Listings Available for Rental by Month 


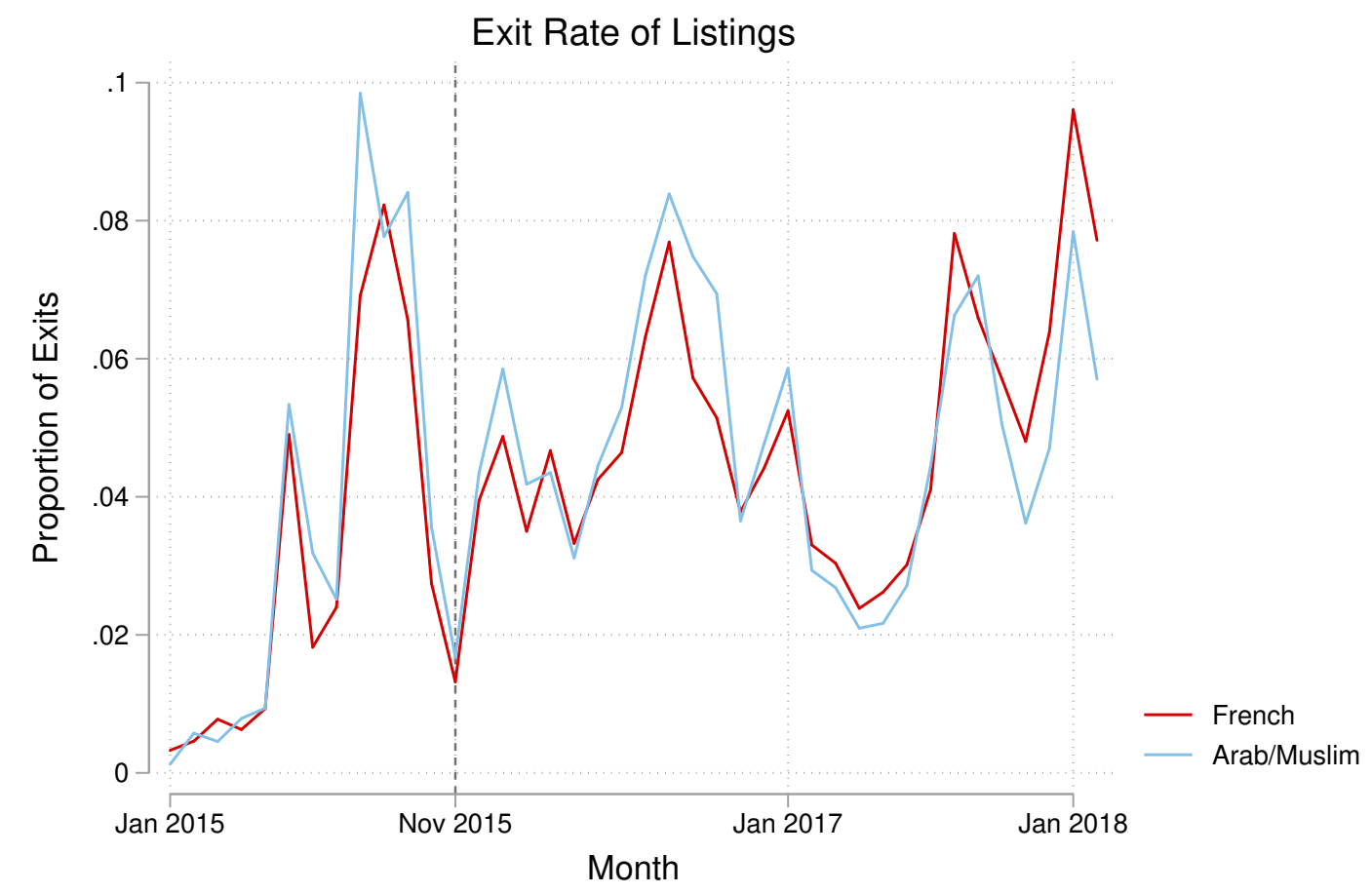

Figure 7: Proportion of Listings Exiting the Airbnb Market Each Month 


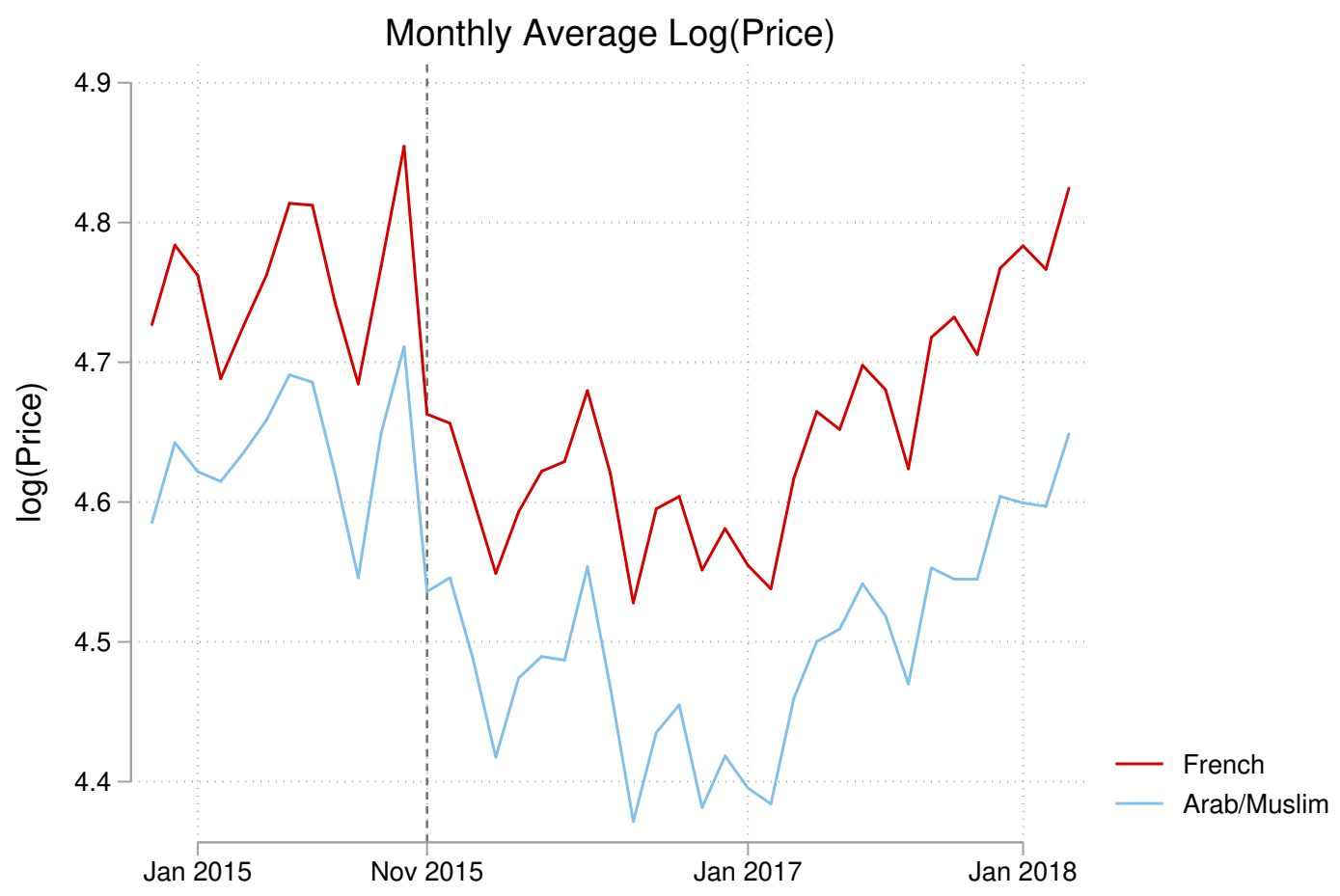

Figure 8: Monthly Average Log(Price) for Listings Rented Out in a Given Month 


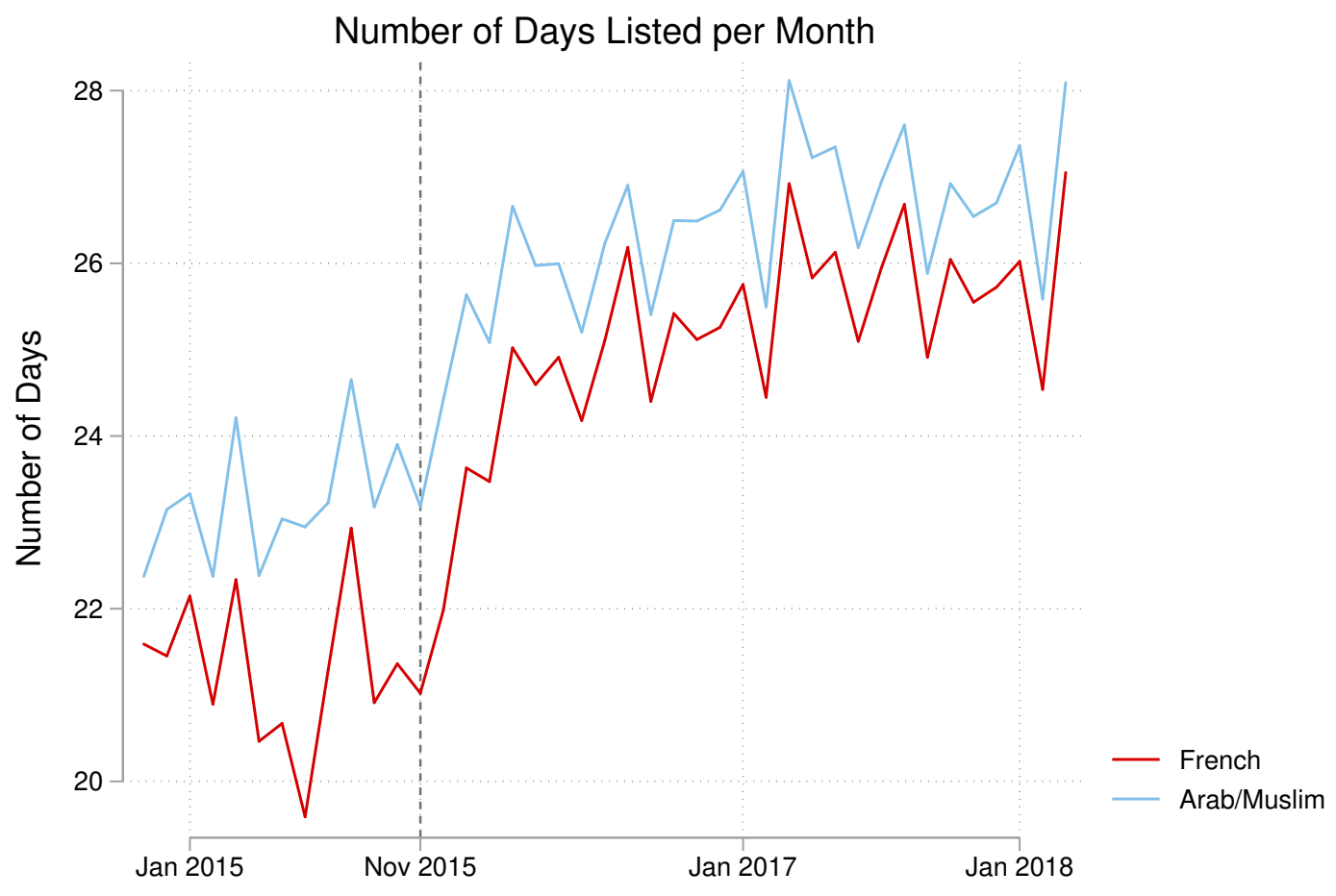

Figure 9: Average Number of Days a Listing is Available for Rental in a Given Month 


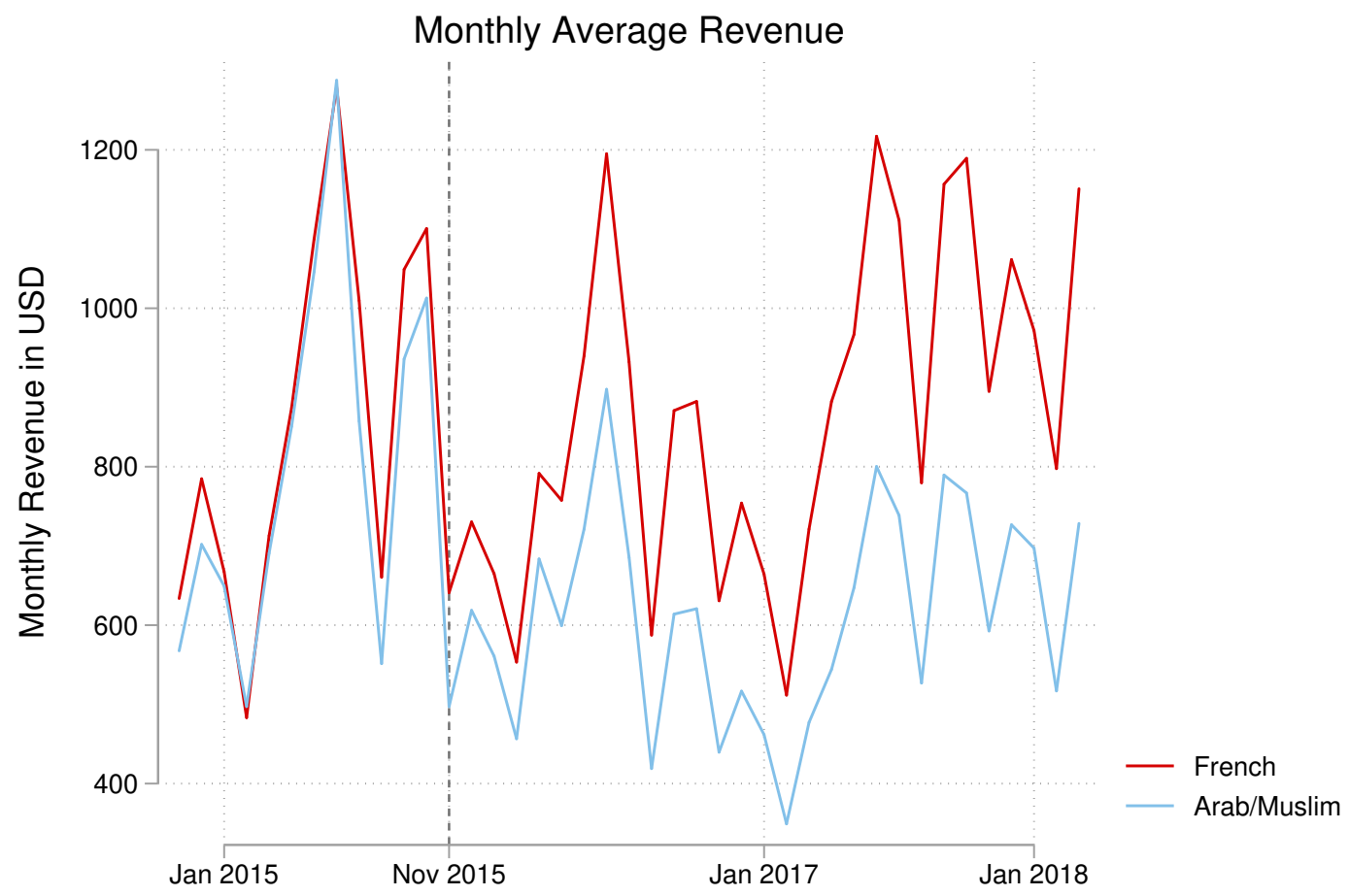

Figure 10: Average Monthly Listing Revenue (Including Listings with Zero Revenue) 
Table 4: Random-Effects Regression for Occupancy Rate and $\log$ (Price)

\begin{tabular}{|c|c|c|c|c|c|c|}
\hline & \multicolumn{3}{|c|}{ Occupancy } & \multicolumn{3}{|c|}{ Log (Price) } \\
\hline & (1) & (2) & (3) & (1) & (2) & (3) \\
\hline Arab/Muslim & $\begin{array}{c}-0.0452^{* * *} \\
(-14.69)\end{array}$ & $\begin{array}{c}-0.0363^{* * *} \\
(-12.67)\end{array}$ & $\begin{array}{c}-0.0317^{* * *} \\
(-10.25)\end{array}$ & $\begin{array}{c}-0.131^{* * *} \\
(-18.09)\end{array}$ & $\begin{array}{c}-0.0602^{* * *} \\
(-14.42)\end{array}$ & $\begin{array}{c}-0.0576^{* * *} \\
(-13.43)\end{array}$ \\
\hline No. of Guests & & $\begin{array}{c}0.00430^{* * *} \\
\quad(6.71)\end{array}$ & $\begin{array}{c}0.00505^{* * *} \\
\quad(7.19)\end{array}$ & & $\begin{array}{c}0.0604^{* * *} \\
(96.85)\end{array}$ & $\begin{array}{c}0.0595^{* * *} \\
(93.59)\end{array}$ \\
\hline No. of photos (x10) & & $\begin{array}{c}0.0524^{* * *} \\
(68.69)\end{array}$ & $\begin{array}{c}0.0300^{* * *} \\
(37.02)\end{array}$ & & $\begin{array}{c}0.0327^{* * *} \\
(47.73)\end{array}$ & $\begin{array}{c}0.0318^{* * *} \\
(46.18)\end{array}$ \\
\hline No. of Bedrooms & & $\begin{array}{c}-0.0377^{* * *} \\
(-26.96)\end{array}$ & $\begin{array}{c}-0.0352^{* * *} \\
(-23.47)\end{array}$ & & $\begin{array}{l}0.265^{* * *} \\
(142.12)\end{array}$ & $\begin{array}{l}0.268^{* * *} \\
(141.24)\end{array}$ \\
\hline No. of Bathrooms & & $\begin{array}{c}-0.0153^{* * *} \\
(-5.66)\end{array}$ & $\begin{array}{c}-0.00547 \\
(-1.90)\end{array}$ & & $\begin{array}{c}0.184^{* * *} \\
(46.65)\end{array}$ & $\begin{array}{c}0.185^{* * *} \\
(46.02)\end{array}$ \\
\hline Instantbook & & $\begin{array}{c}0.0919^{* * *} \\
(82.05)\end{array}$ & $\begin{array}{c}0.0974^{* * *} \\
(79.15)\end{array}$ & & $\begin{array}{c}0.0112^{* * *} \\
(13.89)\end{array}$ & $\begin{array}{c}0.0105^{* * *} \\
(12.88)\end{array}$ \\
\hline Business Ready & & $\begin{array}{c}-0.00665^{* * *} \\
(-6.62)\end{array}$ & $\begin{array}{c}-0.00509^{* * *} \\
(-4.57)\end{array}$ & & $\begin{array}{c}-0.000339 \\
(-0.45)\end{array}$ & $\begin{array}{c}0.000115 \\
(0.15)\end{array}$ \\
\hline Super Host & & $\begin{array}{c}0.0949^{* * *} \\
(59.45)\end{array}$ & $\begin{array}{c}0.0761^{* * *} \\
(44.86)\end{array}$ & & $\begin{array}{c}0.0191^{* * *} \\
(19.46)\end{array}$ & $\begin{array}{c}0.0172^{* * *} \\
(17.44)\end{array}$ \\
\hline Minimum Stay & & $\begin{array}{c}-0.0298^{* * *} \\
(-34.65)\end{array}$ & $\begin{array}{c}-0.0253^{* * *} \\
(-26.33)\end{array}$ & & $\begin{array}{c}-0.0153^{* * *} \\
(-22.12)\end{array}$ & $\begin{array}{c}-0.0143^{* * *} \\
(-20.33)\end{array}$ \\
\hline Cancellation: Moderate & & $\begin{array}{c}0.0982^{* * *} \\
(72.38)\end{array}$ & $\begin{array}{c}0.0785^{* * *} \\
(52.92)\end{array}$ & & $\begin{array}{c}0.00782^{* * *} \\
\quad(7.08)\end{array}$ & $\begin{array}{c}0.00838^{* * *} \\
(7.47)\end{array}$ \\
\hline Cancellation: Strict & & $\begin{array}{c}0.0969^{* * *} \\
(66.26)\end{array}$ & $\begin{array}{c}0.0732^{* * *} \\
(45.58)\end{array}$ & & $\begin{array}{c}0.0294^{* * *} \\
(23.76)\end{array}$ & $\begin{array}{c}0.0276^{* * *} \\
(21.98)\end{array}$ \\
\hline Private Room & & $\begin{array}{c}0.00560^{*} \\
(2.00)\end{array}$ & $\begin{array}{c}-0.00195 \\
(-0.65)\end{array}$ & & $\begin{array}{c}-0.383^{* * *} \\
(-95.74)\end{array}$ & $\begin{array}{c}-0.395^{* * *} \\
(-96.76)\end{array}$ \\
\hline Shared Room & & $\begin{array}{c}0.00392 \\
(0.42)\end{array}$ & $\begin{array}{c}0.00539 \\
(0.52)\end{array}$ & & $\begin{array}{c}-0.763^{* * *} \\
(-55.20)\end{array}$ & $\begin{array}{c}-0.800^{* * *} \\
(-55.98)\end{array}$ \\
\hline No. of Reviews (x10) & & & $\begin{array}{c}0.0212^{* * *} \\
(92.61)\end{array}$ & & & $\begin{array}{c}0.00449^{* * *} \\
(29.26)\end{array}$ \\
\hline Rating: Overall & & & $\begin{array}{c}0.0109^{* * *} \\
(5.73)\end{array}$ & & & $\begin{array}{c}-0.00327^{*} \\
(-2.34)\end{array}$ \\
\hline Rating: Communication & & & $\begin{array}{c}-0.00251 \\
(-1.34)\end{array}$ & & & $\begin{array}{c}-0.00618^{* * *} \\
(-4.70)\end{array}$ \\
\hline Rating: Accuracy & & & $\begin{array}{c}0.0121^{* * *} \\
(7.18)\end{array}$ & & & $\begin{array}{c}-0.00111 \\
(-0.93)\end{array}$ \\
\hline Rating: Cleanliness & & & $\begin{array}{c}0.00431^{* *} \\
(3.07)\end{array}$ & & & $\begin{array}{c}0.0115^{* * *} \\
(11.09)\end{array}$ \\
\hline Rating: Check In & & & $\begin{array}{c}-0.00968^{* * *} \\
(-5.46)\end{array}$ & & & $\begin{array}{c}0.00138 \\
(1.11)\end{array}$ \\
\hline Rating: Location & & & $\begin{array}{c}-0.00511^{* * *} \\
(-3.32)\end{array}$ & & & $\begin{array}{c}-0.00371^{* * *} \\
\quad(-3.32)\end{array}$ \\
\hline Spatial Controls & & $\mathrm{x}$ & $\mathrm{x}$ & & $\mathrm{x}$ & $\mathrm{x}$ \\
\hline Time Controls & $\mathrm{x}$ & $\mathrm{x}$ & $\mathrm{x}$ & $\mathrm{x}$ & $\mathrm{x}$ & $\mathrm{x}$ \\
\hline Observations & 1044022 & 1044022 & 855366 & 522991 & 522991 & 488498 \\
\hline Listings & 72991 & 72991 & 54182 & 65331 & 65331 & 52421 \\
\hline$R^{2}$ & 0.0191 & 0.112 & 0.163 & 0.0207 & 0.685 & 0.695 \\
\hline
\end{tabular}


Table 5: Random-Effects Regression for Price and Revenue in USD

\begin{tabular}{|c|c|c|c|c|c|c|}
\hline & \multicolumn{3}{|c|}{ Price } & \multicolumn{3}{|c|}{ Revenue } \\
\hline Arab/Muslim & $\begin{array}{c}(1) \\
-19.21^{* * *} \\
(-15.20)\end{array}$ & $\begin{array}{c}(2) \\
-8.252^{* * *} \\
(-9.81)\end{array}$ & $\begin{array}{c}(3) \\
-7.676^{\text {*** }} \\
(-9.61)\end{array}$ & $\begin{array}{c}(1) \\
-209.0^{* * *} \\
(-16.62)\end{array}$ & $\begin{array}{c}(2) \\
-103.9^{* * *} \\
(-10.25)\end{array}$ & $\begin{array}{c}(3) \\
-89.30^{* * *} \\
(-7.56)\end{array}$ \\
\hline No. of Guests & & $\begin{array}{c}8.375^{* * *} \\
(67.14)\end{array}$ & $\begin{array}{c}8.585^{* * *} \\
(69.01)\end{array}$ & & $\begin{array}{c}118.0^{* * *} \\
(48.96)\end{array}$ & $\begin{array}{c}143.6^{* * *} \\
(52.15)\end{array}$ \\
\hline No. of photos (x10) & & $\begin{array}{c}4.481^{* * *} \\
(32.77)\end{array}$ & $\begin{array}{c}4.797^{* * *} \\
(35.54)\end{array}$ & & $\begin{array}{c}246.7^{* * *} \\
(85.72)\end{array}$ & $\begin{array}{c}179.0^{* * *} \\
(56.17)\end{array}$ \\
\hline No. of Bedrooms & & $\begin{array}{l}39.00^{* * *} \\
(103.85)\end{array}$ & $\begin{array}{l}38.18^{* * *} \\
(107.11)\end{array}$ & & $\begin{array}{c}80.92^{* * *} \\
(16.11)\end{array}$ & $\begin{array}{c}128.0^{* * *} \\
(22.17)\end{array}$ \\
\hline No. of Bathrooms & & $\begin{array}{c}75.54^{* * *} \\
(95.21)\end{array}$ & $\begin{array}{c}72.66^{* * *} \\
(97.10)\end{array}$ & & $\begin{array}{c}379.0^{* * *} \\
(39.82)\end{array}$ & $\begin{array}{c}526.7^{* * *} \\
(47.89)\end{array}$ \\
\hline Instantbook & & $\begin{array}{c}1.687^{* * *} \\
(10.52)\end{array}$ & $\begin{array}{c}1.752^{* * *} \\
(10.83)\end{array}$ & & $\begin{array}{c}348.1^{* * *} \\
(78.17)\end{array}$ & $\begin{array}{c}356.3^{* * *} \\
(72.02)\end{array}$ \\
\hline Business Ready & & $\begin{array}{l}0.117 \\
(0.78)\end{array}$ & $\begin{array}{l}0.202 \\
(1.33)\end{array}$ & & $\begin{array}{c}39.78^{* * *} \\
(9.79)\end{array}$ & $\begin{array}{c}50.86^{* * *} \\
(11.27)\end{array}$ \\
\hline Super Host & & $\begin{array}{c}2.296^{* * *} \\
(11.74)\end{array}$ & $\begin{array}{c}2.289^{* * *} \\
(11.70)\end{array}$ & & $\begin{array}{c}422.8^{* * *} \\
(65.46)\end{array}$ & $\begin{array}{c}332.4^{* * *} \\
(48.45)\end{array}$ \\
\hline Minimum Stay & & $\begin{array}{c}-2.038^{* * *} \\
(-14.79)\end{array}$ & $\begin{array}{c}-1.936^{* * *} \\
(-13.87)\end{array}$ & & $\begin{array}{c}-122.5^{* * *} \\
(-36.14)\end{array}$ & $\begin{array}{r}-108.0^{* * *} \\
(-28.00)\end{array}$ \\
\hline Cancellation: Moderate & & $\begin{array}{c}-0.436^{*} \\
(-1.98)\end{array}$ & $\begin{array}{l}-0.304 \\
(-1.37)\end{array}$ & & $\begin{array}{c}240.0^{* * *} \\
(45.60)\end{array}$ & $\begin{array}{c}181.8^{* * *} \\
(30.79)\end{array}$ \\
\hline Cancellation: Strict & & $\begin{array}{c}3.192^{* * *} \\
(12.92)\end{array}$ & $\begin{array}{c}3.246^{* * *} \\
(13.08)\end{array}$ & & $\begin{array}{c}301.0^{* * *} \\
(53.46)\end{array}$ & $\begin{array}{c}224.5^{* * *} \\
(35.23)\end{array}$ \\
\hline Private Room & & $\begin{array}{c}-32.98^{* * *} \\
(-40.96)\end{array}$ & $\begin{array}{c}-33.33^{* * *} \\
(-43.75)\end{array}$ & & $\begin{array}{c}-89.02^{* * *} \\
(-8.95)\end{array}$ & $\begin{array}{r}-160.6^{* * *} \\
(-13.93)\end{array}$ \\
\hline Shared Room & & $\begin{array}{c}-49.76^{* * *} \\
(-17.87)\end{array}$ & $\begin{array}{c}-51.22^{* * *} \\
(-19.24)\end{array}$ & & $\begin{array}{c}-177.2^{* * *} \\
(-5.33)\end{array}$ & $\begin{array}{c}-285.5^{* * *} \\
(-7.27)\end{array}$ \\
\hline No. of Reviews (x10) & & & $\begin{array}{c}0.223^{* * *} \\
(7.34)\end{array}$ & & & $\begin{array}{c}83.14^{* * *} \\
(91.07)\end{array}$ \\
\hline Rating: Overall & & & $\begin{array}{c}-1.005^{* * *} \\
(-3.63)\end{array}$ & & & $\begin{array}{c}21.11^{* *} \\
(2.77)\end{array}$ \\
\hline Rating: Communication & & & $\begin{array}{c}-0.916^{* * *} \\
(-3.51)\end{array}$ & & & $\begin{array}{c}-30.39^{* * *} \\
(-4.05)\end{array}$ \\
\hline Rating: Accuracy & & & $\begin{array}{l}-0.243 \\
(-1.03)\end{array}$ & & & $\begin{array}{c}25.25^{* * *} \\
(3.75)\end{array}$ \\
\hline Rating: Cleanliness & & & $\begin{array}{c}2.071^{* * *} \\
(10.13)\end{array}$ & & & $\begin{array}{c}61.14^{* * *} \\
(10.96)\end{array}$ \\
\hline Rating: Check In & & & $\begin{array}{l}0.112 \\
(0.45)\end{array}$ & & & $\begin{array}{r}-29.96^{* * *} \\
(-4.23)\end{array}$ \\
\hline Rating: Location & & & $\begin{array}{l}-0.419 \\
(-1.89)\end{array}$ & & & $\begin{array}{l}-10.46 \\
(-1.71)\end{array}$ \\
\hline Spatial Controls & & $\mathrm{x}$ & $\mathrm{x}$ & & $\mathrm{x}$ & $\mathrm{x}$ \\
\hline Time Controls & $\mathrm{x}$ & $\mathrm{x}$ & $\mathrm{x}$ & $\mathrm{x}$ & $\mathrm{x}$ & $\mathrm{x}$ \\
\hline Observations & 522991 & 522991 & 488498 & 1044022 & 1044022 & 855366 \\
\hline Listings & 65331 & 65331 & 52421 & 72991 & 72991 & 54182 \\
\hline$R^{2}$ & 0.0118 & 0.622 & 0.639 & 0.0179 & 0.243 & 0.291 \\
\hline
\end{tabular}


Table 6: Random-Effects Regression for Occupancy Rate (Price Sample)

\begin{tabular}{|c|c|c|c|}
\hline & (1) & (2) & (3) \\
\hline Arab/Muslim & $\begin{array}{c}-0.0499^{* * *} \\
(-15.03)\end{array}$ & $\begin{array}{c}-0.0462^{* * *} \\
(-16.81)\end{array}$ & $\begin{array}{c}-0.0388^{* * *} \\
(-14.18)\end{array}$ \\
\hline No. of Guests & & $\begin{array}{c}-0.00163^{*} \\
(-2.38)\end{array}$ & $\begin{array}{c}-0.00138^{*} \\
(-2.02)\end{array}$ \\
\hline No. of photos (x10) & & $\begin{array}{c}0.0233^{* * *} \\
(29.62)\end{array}$ & $\begin{array}{c}0.00957^{* * *} \\
(12.31)\end{array}$ \\
\hline No. of Bedrooms & & $\begin{array}{c}-0.0251^{* * *} \\
(-18.31)\end{array}$ & $\begin{array}{c}-0.0237^{* * *} \\
(-17.41)\end{array}$ \\
\hline No. of Bathrooms & & $\begin{array}{c}-0.0156^{* * *} \\
(-6.04)\end{array}$ & $\begin{array}{c}-0.00967^{* * *} \\
(-3.81)\end{array}$ \\
\hline Instantbook & & $\begin{array}{c}0.0645^{* * *} \\
(52.69)\end{array}$ & $\begin{array}{c}0.0668^{* * *} \\
(53.97)\end{array}$ \\
\hline Business Ready & & $\begin{array}{c}0.0101^{* * *} \\
(8.33)\end{array}$ & $\begin{array}{c}0.00847^{* * *} \\
\quad(6.95)\end{array}$ \\
\hline Super Host & & $\begin{array}{c}0.0491^{* * *} \\
(30.25)\end{array}$ & $\begin{array}{c}0.0386^{* * *} \\
(23.92)\end{array}$ \\
\hline Minimum Stay & & $\begin{array}{c}-0.00594^{* * *} \\
(-5.85)\end{array}$ & $\begin{array}{c}-0.000400 \\
(-0.39)\end{array}$ \\
\hline Cancellation: Moderate & & $\begin{array}{c}0.0597^{* * *} \\
(40.02)\end{array}$ & $\begin{array}{c}0.0436^{* * *} \\
(28.97)\end{array}$ \\
\hline Cancellation: Strict & & $\begin{array}{c}0.0565^{* * *} \\
(35.41)\end{array}$ & $\begin{array}{c}0.0393^{* * *} \\
(24.34)\end{array}$ \\
\hline Private Room & & $\begin{array}{c}-0.0206^{* * *} \\
(-7.60)\end{array}$ & $\begin{array}{c}-0.0253^{* * *} \\
(-9.38)\end{array}$ \\
\hline Shared Room & & $\begin{array}{c}-0.0341^{* * *} \\
(-3.77)\end{array}$ & $\begin{array}{c}-0.0314^{* * *} \\
(-3.48)\end{array}$ \\
\hline No. of Reviews (x10) & & & $\begin{array}{c}0.00970^{* * *} \\
(46.03)\end{array}$ \\
\hline Rating: Overall & & & $\begin{array}{c}0.0134^{* * *} \\
(6.72)\end{array}$ \\
\hline Rating: Communication & & & $\begin{array}{c}0.000601 \\
(0.31)\end{array}$ \\
\hline Rating: Accuracy & & & $\begin{array}{c}0.0108^{* * *} \\
(6.24)\end{array}$ \\
\hline Rating: Cleanliness & & & $\begin{array}{c}0.00260 \\
(1.83)\end{array}$ \\
\hline Rating: Check In & & & $\begin{array}{c}-0.00886^{* * *} \\
(-4.86)\end{array}$ \\
\hline Rating: Location & & & $\begin{array}{c}-0.00900^{* * *} \\
(-5.76)\end{array}$ \\
\hline Spatial Controls & & $\mathrm{x}$ & $\mathrm{x}$ \\
\hline Time Controls & $\mathrm{x}$ & $\mathrm{x}$ & $\mathrm{x}$ \\
\hline Observations & 475733 & 522991 & 488498 \\
\hline Listings & 59273 & 65331 & 52421 \\
\hline$R^{2}$ & 0.0409 & 0.0891 & 0.124 \\
\hline
\end{tabular}




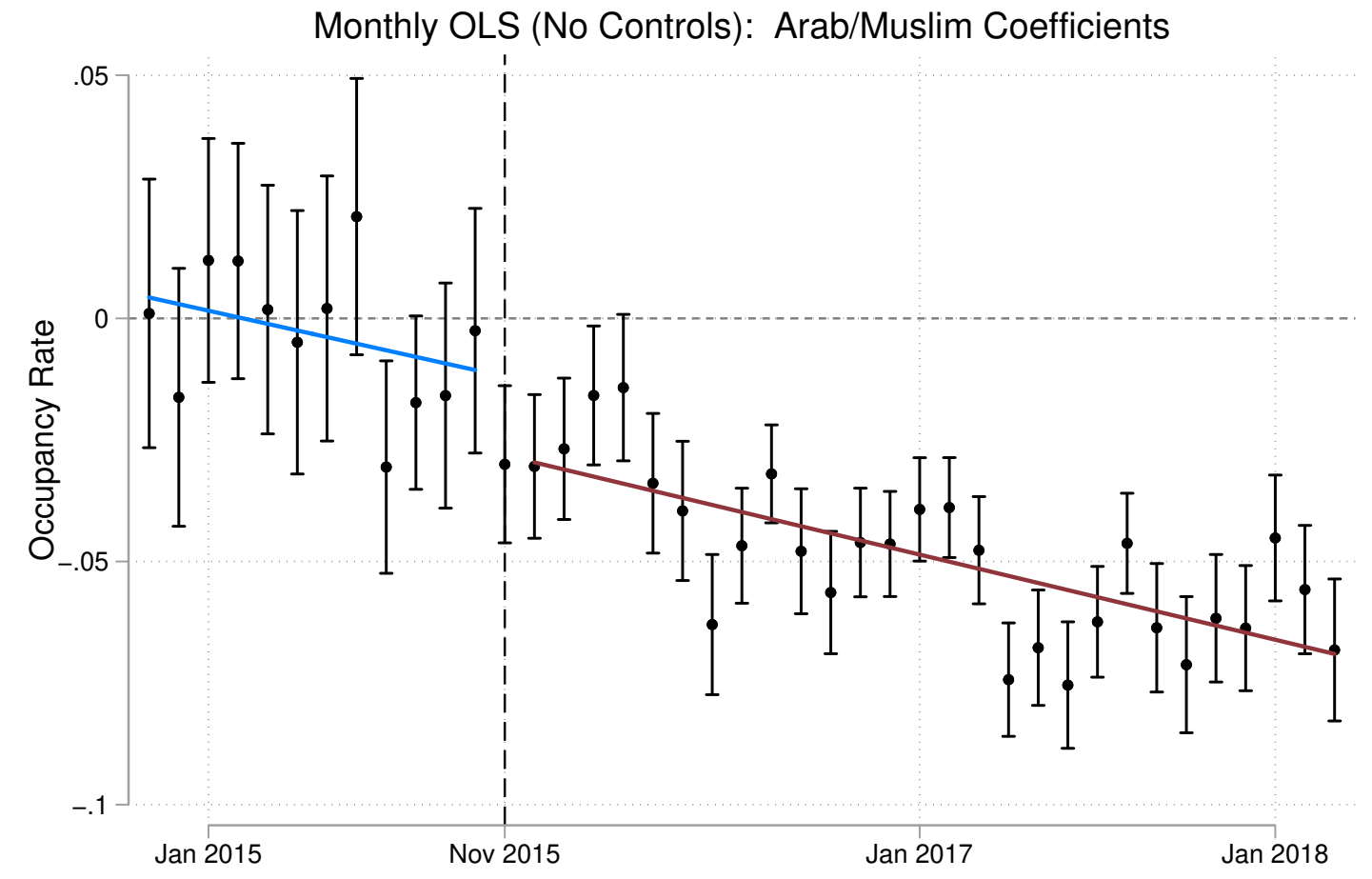

Figure 11: Coefficients and 95\% Confidence Intervals for Hosts with Arab/Muslim Names (From Separate Monthly OLS Regressions with No Controls) 


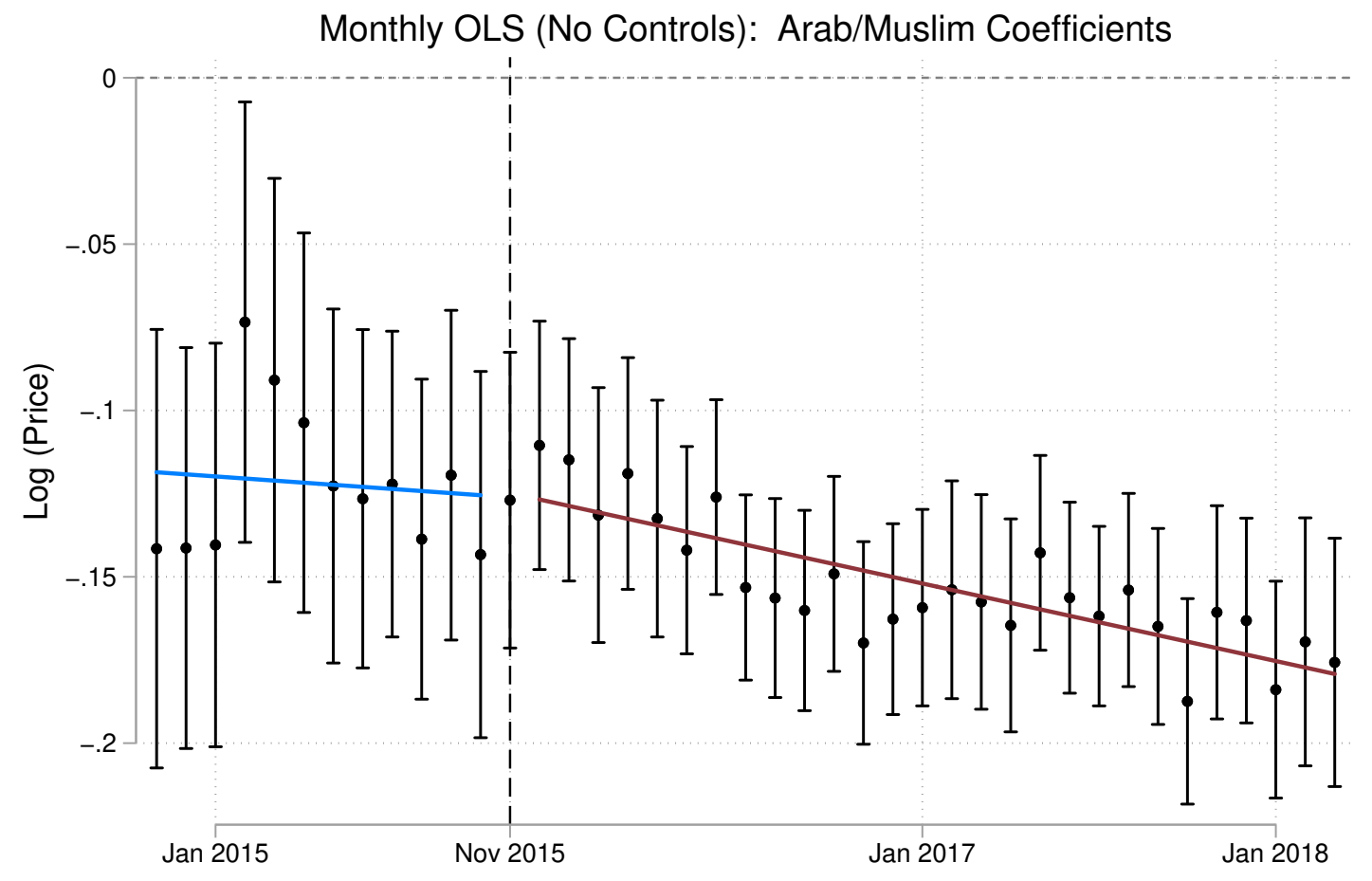

Figure 12: Coefficients and 95\% Confidence Intervals for Hosts with Arab/Muslim Names (From Separate Monthly OLS Regressions with No Controls) 


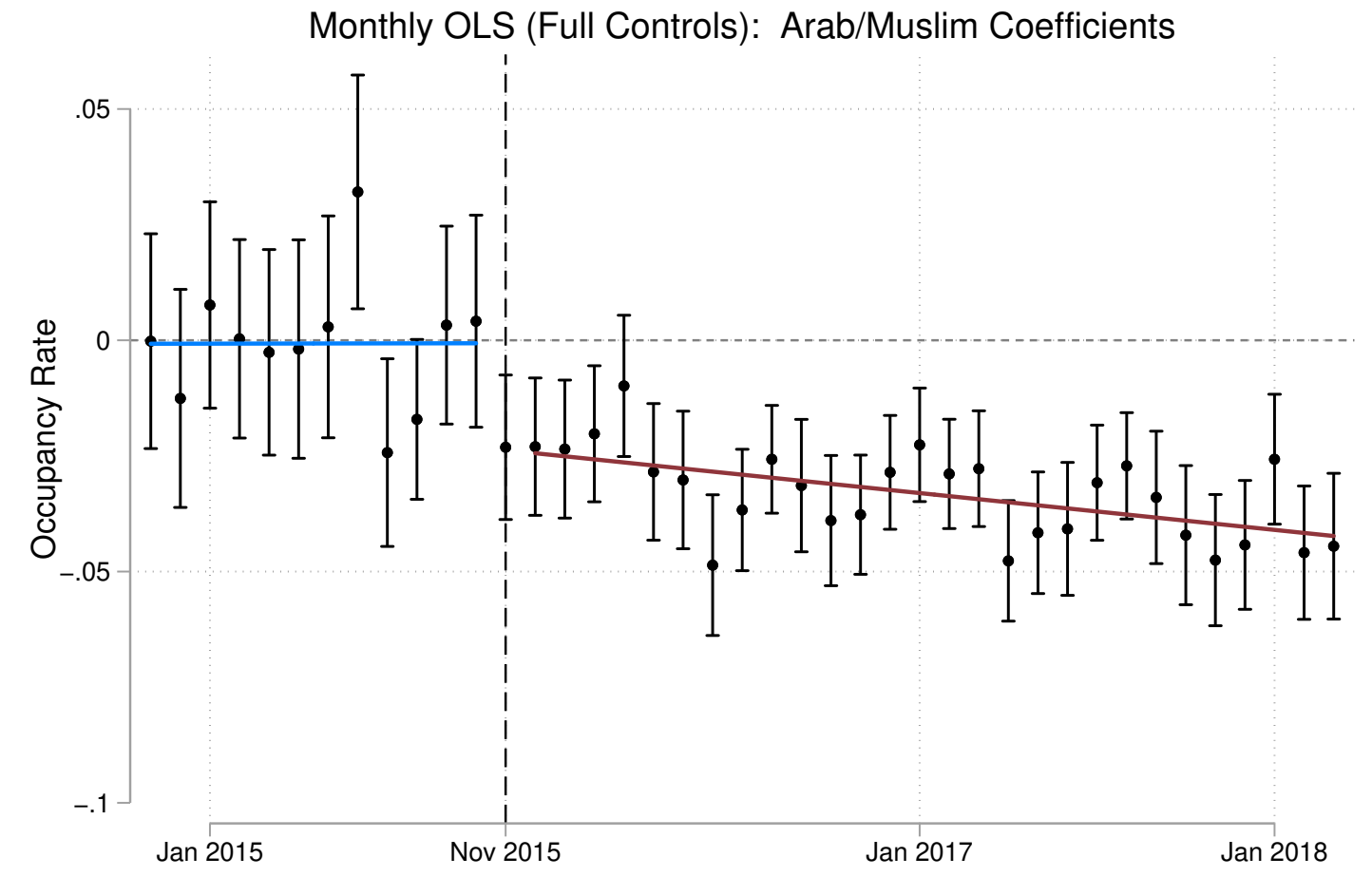

Figure 13: Coefficients and 95\% Confidence Intervals for Hosts with Arab/Muslim Names (From Separate Monthly OLS Regressions with Full Set of Controls, Including Reviews) 


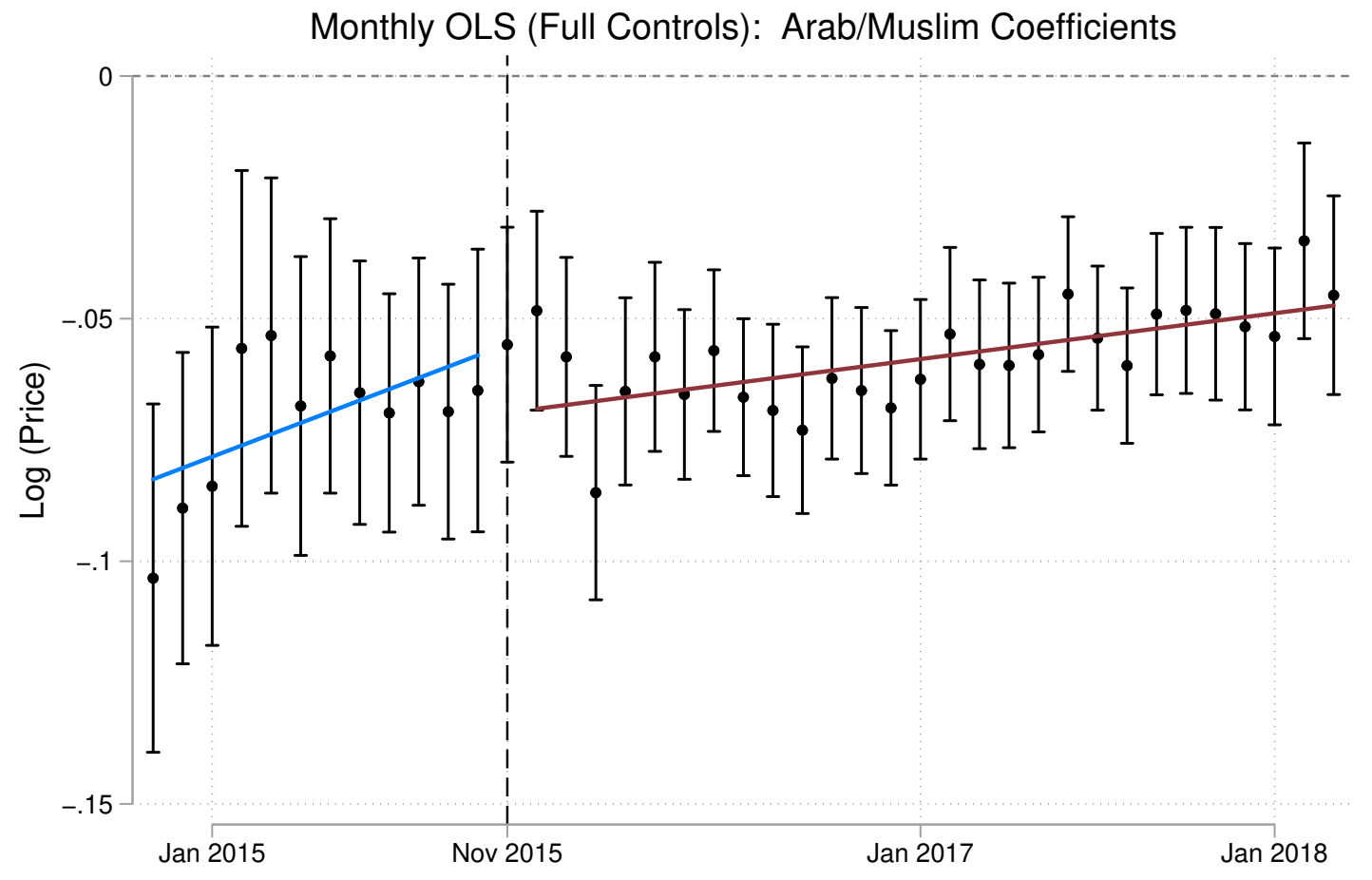

Figure 14: Coefficients and 95\% Confidence Intervals for Hosts with Arab/Muslim Names (From Separate Monthly OLS Regressions with Full Set of Controls, Including Reviews) 


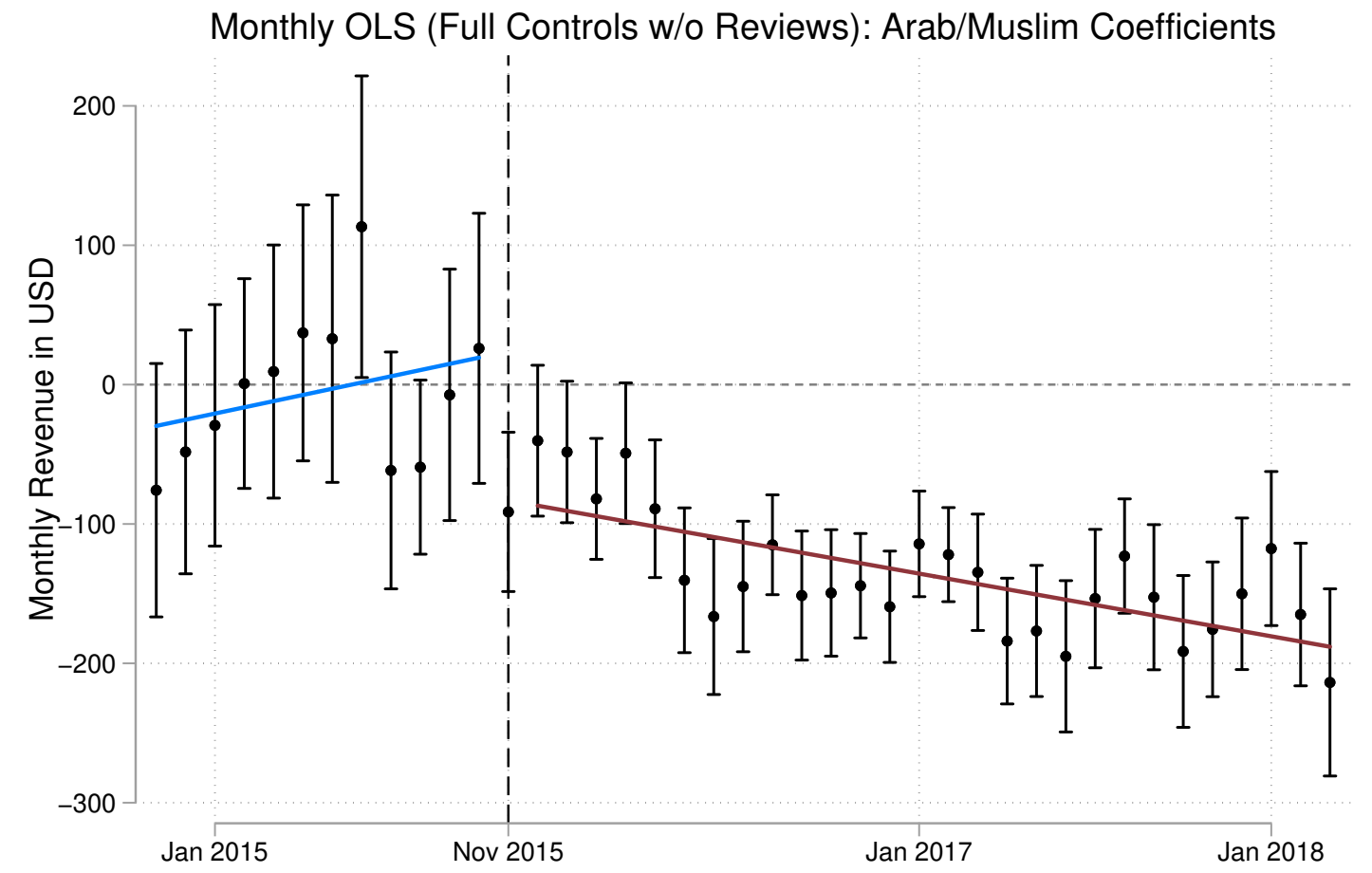

Figure 15: Coefficients and 95\% Confidence Intervals for Hosts with Arab/Muslim Names (From Separate Monthly OLS Regressions with Full Set of Controls, Excluding Reviews) 


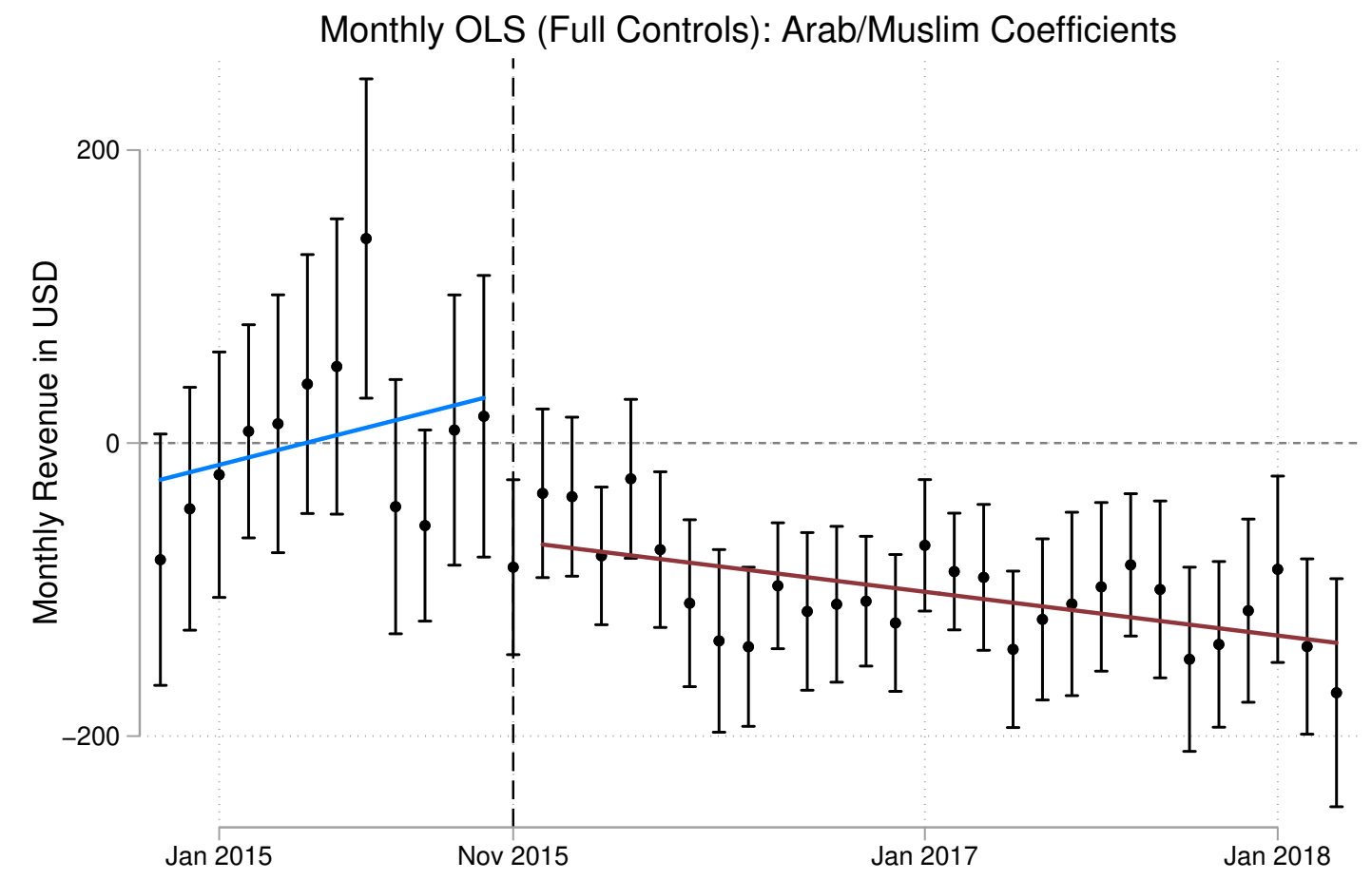

Figure 16: Coefficients and 95\% Confidence Intervals for Hosts with Arab/Muslim Names (From Separate Monthly OLS Regressions with Full Set of Controls, Including Reviews) 


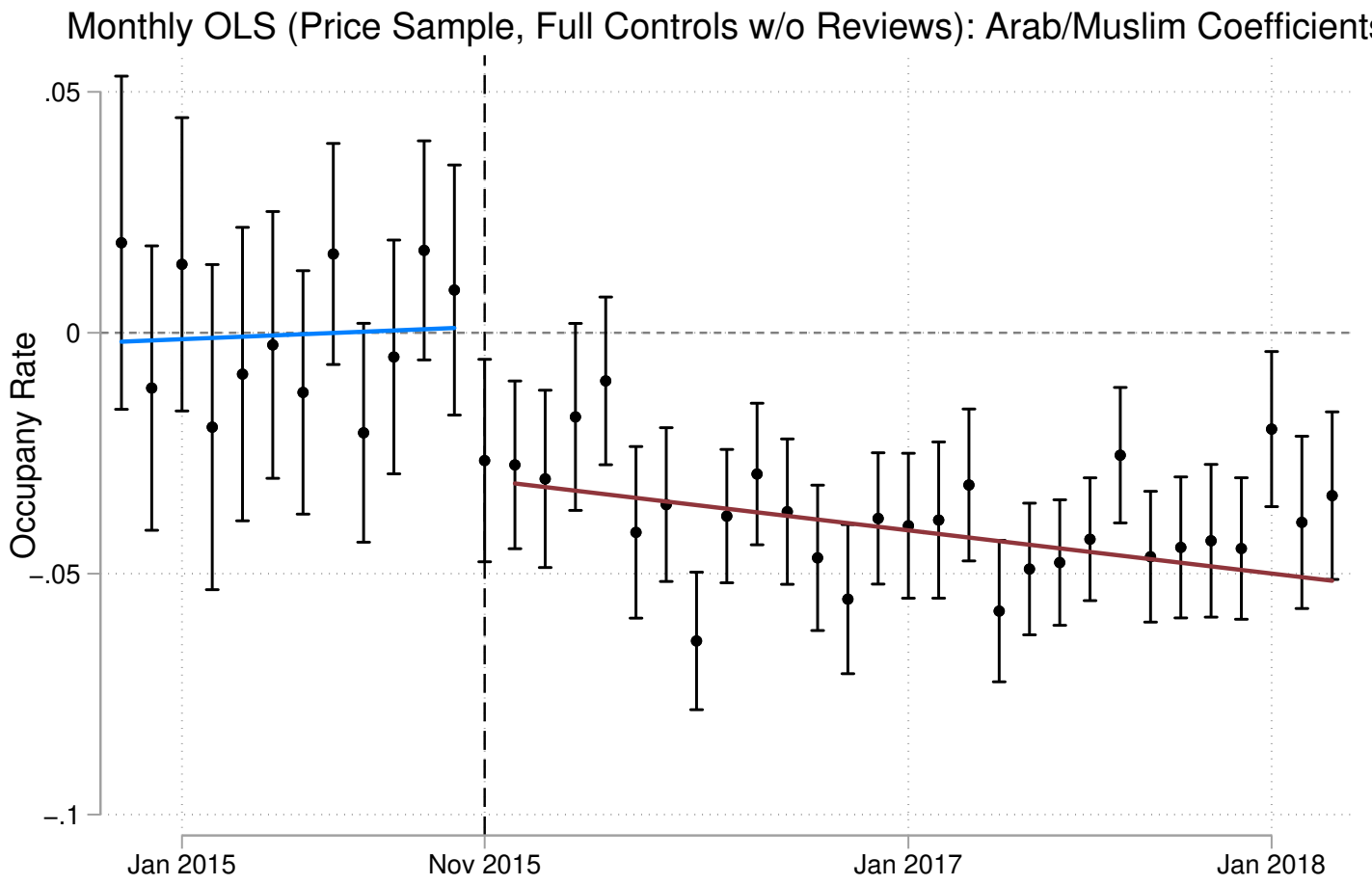

Figure 17: Coefficients and 95\% Confidence Intervals for Hosts with Arab/Muslim Names (From Separate Monthly OLS Regressions with Full Set of Controls, Excluding Reviews) 
Table 7: Estimates From Listing Fixed-Effects Regressions

\begin{tabular}{|c|c|c|c|c|c|c|}
\hline & \multicolumn{3}{|c|}{ Occupancy Rate } & \multicolumn{3}{|c|}{ log(Price) } \\
\hline & (1) & (2) & (3) & (1) & (2) & (3) \\
\hline Post Attacks & $\begin{array}{c}0.000229 \\
(0.26)\end{array}$ & $\begin{array}{c}-0.0125^{* * *} \\
(-13.82)\end{array}$ & $\begin{array}{c}-0.0376^{* * *} \\
(-34.78)\end{array}$ & $\begin{array}{c}-0.0268^{* * *} \\
(-39.92)\end{array}$ & $\begin{array}{c}-0.0339^{* * *} \\
(-49.26)\end{array}$ & $\begin{array}{c}-0.0665^{* * *} \\
(-87.16)\end{array}$ \\
\hline $\mathrm{A} / \mathrm{M} *$ Post Attacks & $\begin{array}{c}-0.0195^{* * *} \\
(-5.97)\end{array}$ & $\begin{array}{c}-0.0228^{* * *} \\
(-7.01)\end{array}$ & $\begin{array}{c}-0.0261^{* * *} \\
(-7.24)\end{array}$ & $\begin{array}{c}-0.0171^{* * *} \\
(-6.69)\end{array}$ & $\begin{array}{c}-0.0184^{* * *} \\
(-7.21)\end{array}$ & $\begin{array}{c}-0.0227^{* * *} \\
(-9.01)\end{array}$ \\
\hline No. of Photos (x10) & & $\begin{array}{c}0.0780^{* * *} \\
(67.70)\end{array}$ & $\begin{array}{c}0.0745^{* * *} \\
(59.17)\end{array}$ & & $\begin{array}{c}0.0218^{* * *} \\
(26.42)\end{array}$ & $\begin{array}{c}0.0153^{* * *} \\
(18.60)\end{array}$ \\
\hline Instantbook & & $\begin{array}{c}0.0744^{* * *} \\
(57.14)\end{array}$ & $\begin{array}{c}0.0731^{* * *} \\
(50.83)\end{array}$ & & $\begin{array}{c}0.0150^{* * *} \\
(16.96)\end{array}$ & $\begin{array}{c}0.00867^{\text {*** }} \\
(9.81)\end{array}$ \\
\hline Business Ready & & $\begin{array}{c}0.0104^{* * *} \\
(10.79)\end{array}$ & $\begin{array}{c}0.0213^{* * *} \\
(19.46)\end{array}$ & & $\begin{array}{c}-0.00866^{* * *} \\
(-12.41)\end{array}$ & $\begin{array}{c}0.00666^{* * *} \\
(9.34)\end{array}$ \\
\hline Super Host & & $\begin{array}{c}0.0694^{* * *} \\
(40.53)\end{array}$ & $\begin{array}{c}0.0555^{* * *} \\
(30.09)\end{array}$ & & $\begin{array}{c}0.0428^{* * *} \\
(41.16)\end{array}$ & $\begin{array}{c}0.0277^{* * *} \\
(26.72)\end{array}$ \\
\hline Minimum Stay & & $\begin{array}{c}-0.0211^{* * *} \\
(-20.68)\end{array}$ & $\begin{array}{c}-0.0237^{* * *} \\
(-20.87)\end{array}$ & & $\begin{array}{c}-0.00355^{* * *} \\
(-4.66)\end{array}$ & $\begin{array}{c}-0.00497^{* * *} \\
(-6.50)\end{array}$ \\
\hline Cancellation: Moderate & & $\begin{array}{c}0.103^{* * *} \\
(59.13)\end{array}$ & $\begin{array}{c}0.103^{* * *} \\
(53.36)\end{array}$ & & $\begin{array}{c}0.0234^{* * *} \\
(18.67)\end{array}$ & $\begin{array}{c}0.0166^{* * *} \\
(13.28)\end{array}$ \\
\hline Cancellation: Strict & & $\begin{array}{c}0.116^{* * *} \\
(59.43)\end{array}$ & $\begin{array}{c}0.112^{* * *} \\
(51.38)\end{array}$ & & $\begin{array}{c}0.0458^{* * *} \\
(32.39)\end{array}$ & $\begin{array}{c}0.0314^{* * *} \\
(22.10)\end{array}$ \\
\hline Rating: Overall & & & $\begin{array}{c}0.0144^{* * *} \\
\quad(5.90)\end{array}$ & & & $\begin{array}{c}-0.00830^{* * *} \\
(-5.28)\end{array}$ \\
\hline Rating: Communication & & & $\begin{array}{c}-0.00139 \\
(-0.60)\end{array}$ & & & $\begin{array}{c}-0.000256 \\
(-0.18)\end{array}$ \\
\hline No. of Reviews (x10) & & & $\begin{array}{c}0.0147^{* * *} \\
(55.55)\end{array}$ & & & $\begin{array}{c}0.0151^{* * *} \\
(104.62)\end{array}$ \\
\hline Rating: Accuracy & & & $\begin{array}{c}0.00614^{* *} \\
(2.92)\end{array}$ & & & $\begin{array}{c}0.00317^{*} \\
(2.42)\end{array}$ \\
\hline Rating: Cleanliness & & & $\begin{array}{c}-0.00190 \\
(-1.02)\end{array}$ & & & $\begin{array}{c}-0.00429^{* * *} \\
(-3.70)\end{array}$ \\
\hline Rating: Check In & & & $\begin{array}{c}-0.00541^{*} \\
(-2.47)\end{array}$ & & & $\begin{array}{c}0.00693^{* * *} \\
(5.06)\end{array}$ \\
\hline Rating: Location & & & $\begin{array}{c}-0.00442^{*} \\
(-2.21)\end{array}$ & & & $\begin{array}{c}0.00402^{* *} \\
(3.23)\end{array}$ \\
\hline Observations & 1026416 & 1026416 & 839390 & 514702 & 514702 & 480427 \\
\hline Listings & 72981 & 72981 & 54175 & 65280 & 65280 & 52390 \\
\hline$R^{2}$ & 0.00186 & 0.0650 & 0.0803 & 0.00904 & 0.185 & 0.0449 \\
\hline
\end{tabular}


Table 8: Estimates From Listing Fixed-Effects Regressions for Revenue

\begin{tabular}{|c|c|c|c|}
\hline & (1) & (2) & (3) \\
\hline Post Attacks & $\begin{array}{c}87.48^{* * *} \\
(24.13)\end{array}$ & $\begin{array}{c}37.48^{* * *} \\
(10.10)\end{array}$ & $\begin{array}{c}-90.74^{* * *} \\
(-20.56)\end{array}$ \\
\hline A/M $*$ Post Attacks & $\begin{array}{c}-107.1^{* * *} \\
(-7.96)\end{array}$ & $\begin{array}{c}-118.7^{* * *} \\
(-8.89)\end{array}$ & $\begin{array}{c}-135.8^{* * *} \\
(-9.24)\end{array}$ \\
\hline No. of Photos (x10) & & $\begin{array}{c}322.7^{* * *} \\
(68.14)\end{array}$ & $\begin{array}{c}298.5^{* * *} \\
(58.14)\end{array}$ \\
\hline Instantbook & & $\begin{array}{c}288.0^{* * *} \\
(53.76)\end{array}$ & $\begin{array}{c}269.6^{* * *} \\
(45.98)\end{array}$ \\
\hline Business Ready & & $\begin{array}{c}30.26^{* * *} \\
(7.60)\end{array}$ & $\begin{array}{c}98.62^{* * *} \\
(22.08)\end{array}$ \\
\hline Super Host & & $\begin{array}{c}338.3^{* * *} \\
(48.05)\end{array}$ & $\begin{array}{c}255.2^{* * *} \\
(33.92)\end{array}$ \\
\hline Minimum Stay & & $\begin{array}{c}-75.27^{* * *} \\
(-17.90)\end{array}$ & $\begin{array}{c}-85.97^{* * *} \\
(-18.53)\end{array}$ \\
\hline Cancellation: Moderate & & $\begin{array}{c}291.9^{* * *} \\
(40.75)\end{array}$ & $\begin{array}{c}273.2^{* * *} \\
(34.84)\end{array}$ \\
\hline Cancellation: Strict & & $\begin{array}{c}385.5^{* * *} \\
(48.02)\end{array}$ & $\begin{array}{c}339.9^{* * *} \\
(38.37)\end{array}$ \\
\hline Rating: Overall & & & $\begin{array}{l}4.124 \\
(0.41)\end{array}$ \\
\hline Rating: Communication & & & $\begin{array}{l}8.051 \\
(0.85)\end{array}$ \\
\hline No. of Reviews (x10) & & & $\begin{array}{c}87.24^{* * *} \\
(80.66)\end{array}$ \\
\hline Rating: Accuracy & & & $\begin{array}{l}12.88 \\
(1.50)\end{array}$ \\
\hline Rating: Cleanliness & & & $\begin{array}{l}-0.505 \\
(-0.07)\end{array}$ \\
\hline Rating: Check In & & & $\begin{array}{l}-6.668 \\
(-0.75)\end{array}$ \\
\hline Rating: Location & & & $\begin{array}{l}1.304 \\
(0.16) \\
\end{array}$ \\
\hline Observations & 1026416 & 1026416 & 839390 \\
\hline Listings & 72981 & 72981 & 54175 \\
\hline$R^{2}$ & 0.00113 & 0.133 & 0.149 \\
\hline
\end{tabular}




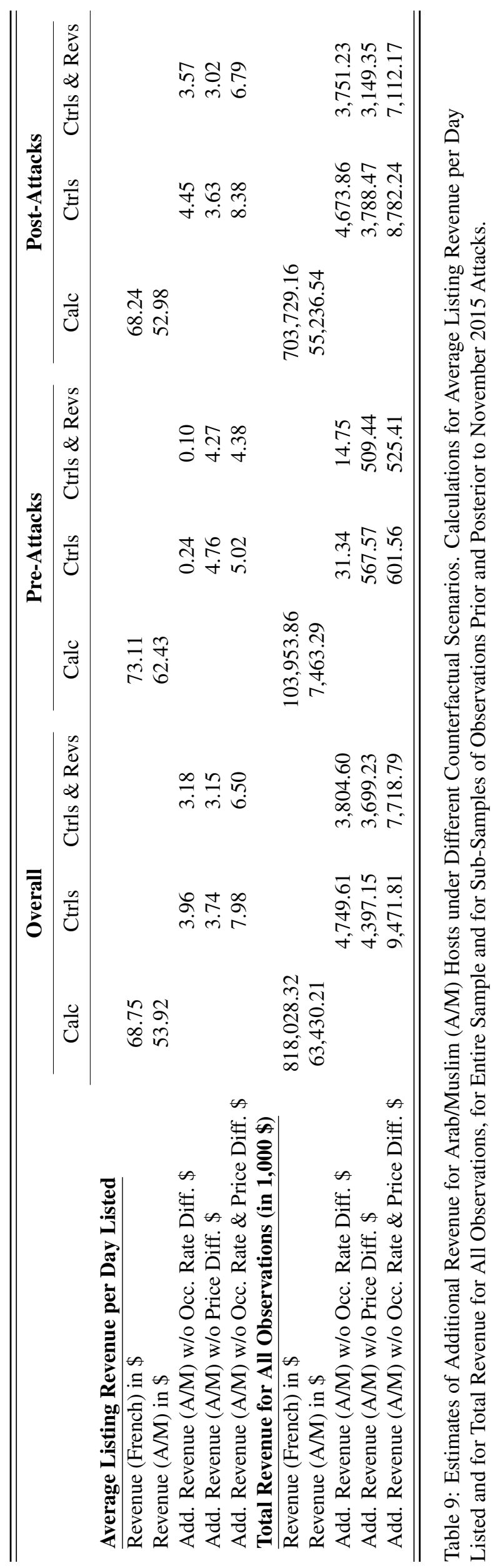




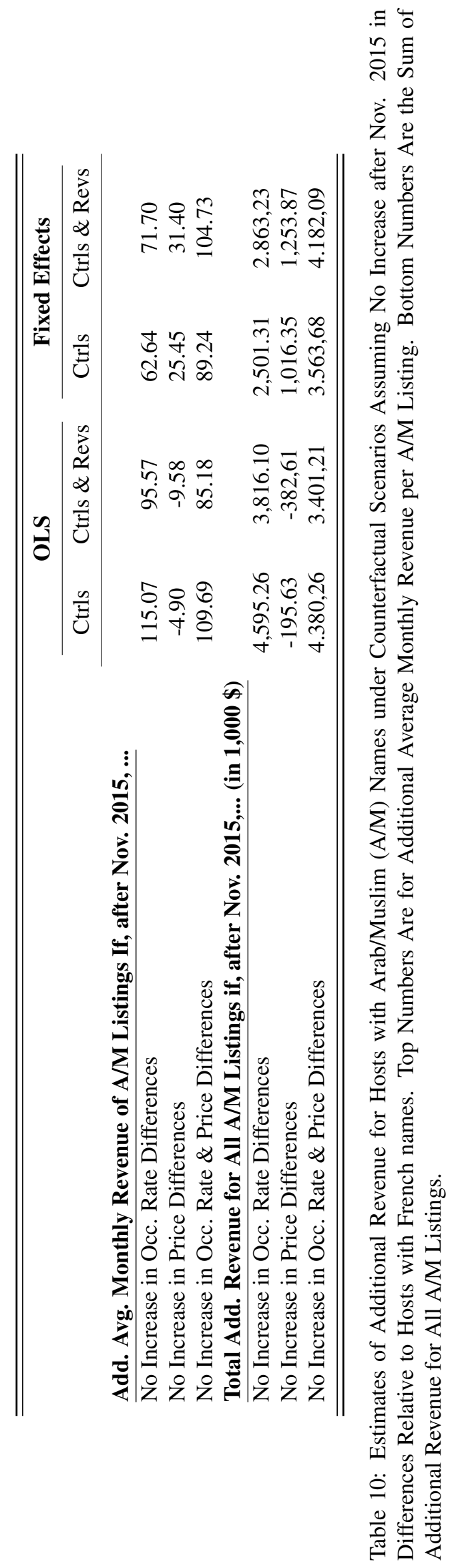

